On welfare losses due to imperfect competition

Robert A. Ritz

July 2012

CWPE 1234 


\title{
On welfare losses due to imperfect competition
}

\author{
Robert A. Ritz* \\ Faculty of Economics \\ Cambridge University \\ rar36@cam.ac.uk
}

This version: July 2012

First version: December 2010

\begin{abstract}
Corporate managers and executive compensation in many industries place significant emphasis on measures of firm size, such as sales revenue or market share. Such objectives have an important - yet thus far unquantified impact on market performance. With $n$ symmetric firms, equilibrium welfare losses are of order $1 / n^{4}$, and thus vanish extremely quickly. Welfare losses are less than $5 \%$ for many empirically relevant market structures, despite significant firm asymmetry and industry concentration. They can be estimated using only basic information on market shares. These results also apply to oligopsonistic competition (e.g., for retail bank deposits) and strategic forward trading (e.g., in restructured electricity markets).

Keywords: Delegation, forward trading, managerial incentives, market structure, welfare losses.

JEL classifications: D43, D61, L13, L22, L41.
\end{abstract}

${ }^{*}$ My thanks are due to Patrick Legros (the Editor) and three referees for comments which helped me improve the paper, and to Alberto Behar, Kohei Kawamura and John Quah for useful discussions of earlier drafts. 


\section{Introduction}

For imperfectly competitive markets, the profit-maximization hypothesis (see, e.g., Alchian, 1950 and Friedman, 1953) lacks the strong foundation that it enjoys under perfect competition. Firms' strategic departures from profit-maximization have important consequences for market performance. This paper shows that welfare losses due to imperfect competition are often small when firms (or their managers) pursue additional objectives such as sales revenue or market share. For example, in a symmetric linear duopoly, equilibrium welfare losses are only 4 percent. In other words, 96 percent of the maximum possible social surplus is realized even in a highly concentrated market with only two sellers.

Welfare losses due to imperfect competition have received much attention from economists, especially since Harberger's (1954) controversial estimate that deadweight losses from monopoly power in U.S. manufacturing are less than 0.1 percent of GNP. While some other empirical studies have obtained similar estimates, others have found that welfare losses are significantly higher in the range of 4 to 7 percent of GNP or above (see, e.g., Cowling and Mueller, 1978). As a result, there has been considerable debate about the appropriate empirical methodology to estimate welfare losses, and, relatedly, about the limitations of available industry data (especially on firm profits). ${ }^{1}$

More recently, on the theoretical side, Anderson and Renault (2003) examine welfare losses under Cournot competition (with symmetric firms and homogeneous products), and provide bounds in terms of the number of firms in the market and demand conditions. Corchón (2008) shows that, although welfare losses are typically quite small for Cournot competition with symmetric firms, they can be much larger when firms have asymmetric costs.

Existing contributions to the literature assume either explicitly or implicitly that firms are profit-maximizers. However, extensive evidence suggests that, in practice, managers also place much emphasis on measures of their firm's size, such as sales revenue or market share. For example, competition for rankings in "league tables" - based on size rather than profits - plays an important role in many sectors.

In the banking industry, information providers such as Thomson Financial and Dealogic compile league tables based on the dollar volume of sales (rather than profitability) for different lines of business such as syndicated loans, initial public offerings, and mergers \& acquisitions. Industry reports make it plain that league table rankings are a significant source of managerial utility, and that banks are

\footnotetext{
${ }^{1}$ See Scherer and Ross (1990) for a detailed overview of this literature.
} 
willing to sacrifice profits to improve their position. ${ }^{2}$

The rivalry between Airbus and Boeing in aircraft manufacturing focuses heavily on the volume of plane orders and deliveries, with former Airbus chairman Alan Boyd admitting to a strategy of "pricing for market share" (Yoffie, 1991). General Electric famously pursued for many years the objective of being the largest or second-largest firm (by sales) in each of its businesses. Similar objectives also feature prominently in the semiconductor, automotive, and computer industries, as well as in competition between stock exchanges. ${ }^{3}$

Moreover, there is substantial evidence that executive compensation is positively tied to firm size (in addition to profits). Such a relationship has been found to hold empirically across many different countries and over time, for both manufacturing and service industries (see, e.g., Murphy, 1999 and Rosen, 1992) and in the banking sector (see, e.g., Hubbard and Palia, 1995). Perhaps one of the earliest examples of the impact of revenue-based managerial incentive contracts on competition comes from the Dutch East India Company in the $17^{\text {th }}$ century (Irwin, 1991).

The separation of ownership and control can function as a strategic commitment to aggressive behaviour in product markets. In particular, it can be a profitmaximizing strategy for a firm's shareholders to use incentive contracts that reward sales revenue in addition to profits (see Vickers, 1985 and Fershtman and Judd, 1987). ${ }^{4}$ Thus, the industry ends up in a prisoners' dilemma: Collectively, it would be better off under profit-maximization but, individually, it is in each firm's interest to use sales incentives. ${ }^{5}$ An alternative interpretation of these models is that managers propose such product-market strategies to shareholders, and the capital market selects among competing proposals.

\footnotetext{
${ }^{2}$ For example, a recent press comment notes that "rival investment banks will now be carefully assessing whether to try and muscle in ... in order not to miss out on the fees and the valuable league table credit so beloved of banks' marketing departments" (Financial Times, 1 March 2010), while another concludes "it is time the banks stopped being so obsessed with league tables and concentrated on generating revenues for their own shareholders" (Financial Times, 22 April 2007).

${ }^{3}$ See, e.g., The Economist, 2 April 2009 on competitive conditions in semiconductors, Ritz (2008) on incentives and compensation in the automotive industry, Berkson, Maged, Shah and Tantzen (1997) on sales objectives in the U.S. computer industry, and Capaldo, Härle and Marrs (2008) on competition between stock exchanges.

${ }^{4}$ These build on the insights of Schelling (1960) on the value of third-party commitment and on the game-theoretical results of d'Aspremont and Gérard-Varet (1980). The result that managers' incentive contracts reward sales revenue relies on competition between firms being in strategic substitutes (as is typically the case in Cournot markets).

${ }^{5}$ Other models in which size matters include those with switching costs and network effects; see Farrell and Klemperer (2007) for a recent survey. In contrast to strategic incentives, these tend to revolve around intertemporal aspects of pricing and production. Moreover, size components enter directly into a firm's value function, so it is not clear why managerial incentives are separately based on sales revenue. See also Zábojnik (1998) for a model in which sales incentives help strengthen employee investment in specific human capital.
} 
How large are welfare losses due to imperfect competition when firms employ strategic incentives? While it is well-known that such departures from profit-maximization lead to lower prices, only very little attention has been paid to actually quantifying their welfare impact.

This paper shows that, in the case with $n$ symmetric firms, welfare losses are of order $1 / n^{4}$, and thus vanish extremely quickly. With at least three symmetric firms, welfare losses are always less than 1 percent. So over 99 percent of maximum possible social surplus is realized in the incentive equilibrium (see Proposition 2). Amongst other things, this result closely matches Bresnahan and Reiss's (1991) empirical finding that entry beyond a third firm has virtually no further effect on the competitiveness of a market.

With asymmetric firms, welfare losses are higher because an inefficiently large fraction of industry output is produced by high-cost/low-quality firms. However, with equilibrium incentives, an additional efficiency effect arises compared to profit maximization: Since competition is more intense under delegation, firms with lower costs (or higher product quality) capture larger market shares than in standard Cournot markets. Put differently, for a weaker firm to sustain a given - empirically observed - market share, its disadvantage relative to other firms must be smaller under delegation. This effect very significantly limits deadweight losses due to imperfect competition.

Incorporating firms' strategic incentives, welfare losses due to imperfect competition are below 5 percent for many empirically relevant market structures - despite significant firm asymmetry and industry concentration. For example, a simple sufficient condition for welfare losses to be less than 5 percent is that the market share of the largest firm in the industry does not exceed 35 percent (see Proposition 4). ${ }^{6}$ Welfare losses are also small if firms' unit costs and product qualities are sufficiently similar, or if there are sufficiently many firms in the industry (see Proposition 3 ). ${ }^{7}$

The paper derives these results based on a formula for equilibrium welfare losses that uses only basic information on the distribution of firms' market shares (see Proposition 1). Such industry data are often readily available to the analyst, making it straightforward to put the formula into practice and estimate welfare losses for a particular industry.

These results apply to a range of other settings in which competition between

\footnotetext{
${ }^{6}$ This condition is satisfied for many real-world industries (see Section 6 for more discussion). Note also that a combined market share of no more than 35 percent for merging firms is often considered to be a "safe harbour" under the 1992 U.S. Horizontal Merger Guidelines.

${ }^{7}$ Note especially that none of these conditions are valid, in general, for Cournot competition with profit-maximizing firms.
} 
firms shares the same underlying strategic properties. For instance, they apply equally to oligopsonistic markets in which managers pursue strategic incentives. One topical example is competition between commercial banks for retail deposits (one of their core business activities). There is a strong policy interest in the market structure of the banking sector following the 2007-9 financial crisis. ${ }^{8}$ The results presented in this paper can be used to estimate welfare losses in a standard model of deposit market competition, based on the observed distribution of banks' market shares.

A further application is the impact of forward trading on market performance, which has recently received much attention in restructured electricity markets in the U.K. and several U.S. states (see, e.g., Green, 1999 and Bushnell, Mansur and Saravia, 2008). This paper shows that the seminal two-period forward contracting model due to Allaz and Vila (1993) is strategically equivalent to the two-stage model of managerial delegation. Propositions 1 to 4 thus directly quantify equilibrium welfare losses, and provide conditions under which deadweight losses with strategic forward contracting are less than 5 percent. This contrasts with much of the existing empirical literature on deregulated electricity markets that focuses on estimating price-cost margins (Lerner indices) as a proxy for welfare losses due to market power.

The remainder of the paper is organized as follows. Section 2 sets up the benchmark model, and Section 3 derives its equilibrium conditions. Section 4 presents a formula for equilibrium welfare losses. Section 5 discusses the case with symmetric firms, while Section 6 analyzes the model with asymmetric firms. Section 7 presents applications to competition between oligopsonists and strategic forward trading.

Section 8 discusses several extensions. Extension A considers non-linear demand curves, and Extension B covers settings where entering firms incur a fixed setup cost. These show that the basic insights from the analysis - and the 5 percent upper bound on welfare losses - extend well beyond the benchmark model. Extension $\mathrm{C}$ analyzes a general model with non-linear demand curves, a fixed setup cost, and a generalized welfare function that may place greater weight on consumer welfare. Using an equilibrium formula for generalized welfare losses (see Proposition 5), it shows that losses tend to zero if either the number of firms grows large or if firms' demand curves are sufficiently convex (see Proposition 6). ${ }^{9}$

Section 9 offers concluding remarks.

\footnotetext{
${ }^{8}$ For example, there are concerns about competition in the U.K. banking sector, notably since the merger of HBOS and Lloyds TSB (two of the largest commercial banks) in late 2008.

${ }^{9}$ This extension also shows that - in contrast to standard Cournot competition - it is not possible to construct examples in which (generalized) welfare losses are arbitrarily close to 100 percent in settings where firms pursue strategic incentives.
} 


\section{Benchmark model}

Industry parameters. Consider an industry with $n \geq 2$ quantity-setting firms. Firm $j$ has unit cost $c_{j}$, produces output $x_{j}$, and has market share $\sigma_{j}=x_{j} / X$ (where $X \equiv \sum_{j=1}^{n} x_{j}$ is industry output). Let $c_{\min } \equiv \min _{j} c_{j}$ denote the lowest unit cost, and let $\sigma_{\max } \equiv \max _{j} \sigma_{j}$ denote the highest market share.

On the demand side, consumer utility is given by

$$
U\left(x_{1}, \ldots, x_{n}\right)=\sum_{j=1}^{n} \alpha_{j} x_{j}-X^{2} / 2 s .
$$

Letting $p_{j}$ denote firm $j$ 's price, utility maximization yields a linear inverse demand curve for firm $j$,

$$
p_{j}(X)=\alpha_{j}-X / s
$$

where $\alpha_{j}$ is a measure of demand for firm $j$ 's product and $s>0$ is a measure of market size. ${ }^{10}$

This setup allows for both cost asymmetry (in the $c_{j}$ s) and demand asymmetry (in the $\alpha_{j} \mathrm{~s}$ ) between firms. Demand asymmetry can be interpreted as reflecting differences in product quality, that is, as vertical product differentiation. Thereby, consumers have a higher willingness-to-pay for a higher-quality product. ${ }^{11}$

It will be useful to let $\lambda_{j} \equiv\left(\alpha_{j}-c_{j}\right)>0$ denote a profitability index for firm $j$, and also let $\lambda_{\max } \equiv \max _{j} \lambda_{j}$. All else equal, a firm will be more profitable if it has higher product quality or lower unit costs.

Strategic incentives. Firms delegate decision-making in the product market to their managers. Manager $j$ maximizes

$$
\Omega_{j}=\left(1-\theta_{j}\right) \Pi_{j}+\theta_{j} R_{j}
$$

a weighted average of firm profits $\Pi_{j}=\left(p_{j}-c_{j}\right) x_{j}$ and sales revenue $R_{j}=p_{j} x_{j}$.

The game has two stages. In the first stage, each firm's shareholders choose the incentive weight $\theta_{j}$ to maximize their firm's profits $\Pi_{j}$. In the second stage, each firm's manager chooses an output level $x_{j}$ to maximize his objective $\Omega_{j}$.

Managers' payoffs are held to their outside option (which is normalized to zero),

\footnotetext{
${ }^{10}$ The main implication of the linear demand structure is that competition is in strategic substitutes, so firms want to commit to more rather than less aggressive behaviour in product markets. See Extensions A and C in Section 8 for further analysis with non-linear demand systems.

${ }^{11}$ For example, some computers (or computer parts) are more reliable than others (even though they may all be functionally almost identical), some financial institutions provide a faster or more efficient service than others, and different quality grades exist for numerous "commodity" products such as aluminium, cement, crude oil, and steel.
} 
so all rents accrue to shareholders.

This paper follows the applied literature in assuming that such product-market incentives form a credible commitment. A sufficient condition for this is that managers' contracts are observable and non-renegotiable. The standard justification, given by Fershtman and Judd (1987), is that incentive contracts, in practice, are in force for substantial periods of time, and that firms and managers eventually learn about the prevailing incentive structure in their industry.

However, commitment value can obtain more generally in some settings. For example, in an important paper, Caillaud, Jullien and Picard (1995) show that (only) precommitments towards more aggressive behaviour - as considered in the present analysis - may be credible even when renegotiation is allowed. ${ }^{12}$ See, e.g., Fershtman and Kalai (1997), Katz (1991, 2006), and Koçkesen and Ok (2004) for further discussion and analysis of conditions under which credible commitments are possible.

Social welfare. Social welfare is defined as the sum of consumer and producer surplus, $W\left(x_{1}, \ldots, x_{n}\right)=\left[U\left(x_{1}, \ldots, x_{n}\right)-\sum_{j=1}^{n} p_{j} x_{j}\right]+\sum_{j=1}^{n} \Pi_{j}$, or equivalently

$$
W\left(x_{1}, \ldots, x_{n}\right)=\sum_{j=1}^{n} \lambda_{j} x_{j}-X^{2} / 2 s
$$

The marginal social surplus for product $j$ is $\partial W / \partial x_{j}=\lambda_{j}-X / s$. Thus, "first-best" social welfare involves industry output $X^{F B}=s \lambda_{\max }$ and so

$$
W^{F B}=(s / 2) \lambda_{\max }^{2}
$$

The highest possible social welfare is achieved where all industry output is produced by the firm with the highest profitability index $\lambda_{\max }$ (that is, the highest difference between product quality and unit cost). With symmetric product qualities (so $\alpha_{j}=\alpha$ for all $j$ ), there is a single market price that in first-best is equal to the unit cost of the most efficient firm, $p=c_{\min }$.

The main objective of the analysis is to quantify the (percentage) welfare loss due to imperfect competition,

$$
L=1-W / W^{F B},
$$

which is also known as the relative deadweight loss; see, e.g., Tirole (1988).

\footnotetext{
${ }^{12}$ However, Reitman (1993) shows that non-linear incentives derived from stock options can mitigate — and sometimes even fully offset — the pro-competitive effect of strategic incentives.
} 


\section{Equilibrium conditions}

The game is solved backwards for the subgame-perfect Nash equilibrium. Manager $j$ 's first-order condition in stage two (taking the incentive weight $\theta_{j}$ as given) is

$$
\frac{\partial \Omega_{j}}{\partial x_{j}}=\left(1-\theta_{j}\right) \frac{\partial \Pi_{j}}{\partial x_{j}}+\theta_{j} \frac{\partial R_{j}}{\partial x_{j}}=0 .
$$

This condition implicitly defines manager $j$ 's best response in the product market. The Nash equilibrium of the stage occurs where all managers are simultaneously playing their best responses. Thus let $x_{j}^{*}\left(\theta_{1}, \ldots, \theta_{n}\right)$ denote the equilibrium output of firm $j$ as a function of all managers' incentive weights.

Note that these first-order conditions also determine the aggregate best response of other firms to a change in firm $j$ 's output

$$
\frac{d X_{-j}}{d x_{j}}=\frac{\sum_{k \neq j} \partial^{2} \Omega_{k} / \partial x_{k} \partial x_{j}}{-\sum_{k \neq j} \partial^{2} \Omega_{k} / \partial x_{k} \partial X_{-j}} \equiv \psi_{-j},
$$

where $X_{-j}=\sum_{k \neq j} x_{k}$.

Given the Nash equilibrium in the second stage, shareholders strategically choose their manager's incentives in the first stage. The first-order condition for firm $j$ can be written as

$$
\frac{d \Pi_{j}^{*}}{d \theta_{j}}=\left[p_{j}\left(X^{*}\right)-c_{j}+p_{j}^{\prime}\left(X^{*}\right) x_{j}^{*}\left(1+\psi_{-j}\right)\right] \frac{d x_{j}^{*}}{d \theta_{j}}=0
$$

where a higher weight on sales revenue increases manager $j$ 's output choice, $d x_{j}^{*} / d \theta_{j}>$ $0 .{ }^{13}$ The strategic effect $\psi_{-j}$ induces deviations from profit-maximization.

Combining the two first-order conditions for firm $j$ shows that equilibrium incentives are characterized by $\theta_{j}^{*} c_{j}=p_{j}^{\prime}\left(X^{*}\right) x_{j}^{*} \psi_{-j}$. Whenever competition is in strategic substitutes, $\psi_{-j}<0$, firm $j$ 's manager is given aggressive incentives for sales revenue with $\theta_{j}^{*}>0$. This induces the manager to expand output beyond the profit-maximizing level, thus reducing profit margins and increasing social surplus.

\section{Welfare losses}

Incentives based on sales revenue induce parallel, outward shifts in firms' best response curves without changing their slopes. To see why, note from (8) that the

\footnotetext{
${ }^{13}$ This intuitive result follows by implicitly differentiating (7), using the second-order conditions to verify that $\partial x_{j}^{*} / \partial \theta_{j}>0$, and then noting that $\operatorname{sign}\left(d x_{j}^{*} / d \theta_{j}\right)=\operatorname{sign}\left(\partial x_{j}^{*} / \partial \theta_{j}\right)$ by the stability of equilibrium.
} 
strategic effect $\psi_{-j}$ depends only on the second-order properties of the other managers' objective functions, $\Omega_{k}(k \neq j)$. Firm $k$ 's marginal revenue is simply marginal profit plus marginal cost, $\partial R_{k} / \partial x_{k}=\partial \Pi_{k} / \partial x_{k}+c_{k}$. Thus, its objective function $\Omega_{k}$ inherits the strategic properties of the underlying profit function $\Pi_{k}$, and the slopes of firms' best responses curves are exactly the same as in a standard Cournot model. ${ }^{14}$

With linear demand, the strategic effect from (8) becomes

$$
\psi_{-j}=-\left(1-\frac{1}{n}\right) \equiv \psi^{*}
$$

Note that $\psi^{*}<0$, so competition is indeed in strategic substitutes (and so incentive contracts place positive weight on sales revenue, $\theta_{j}^{*}>0$ for all $j$ ), and also that $\psi^{*}$ is a constant that is common to all firms. Any asymmetries in unit costs or product quality thus also only affect the levels but not the slopes of best responses. Finally, observe that $\psi^{*} \rightarrow-1$ as the number of firms grows large - intuitively, there is more scope for strategic manipulation with more firms in the market.

Using the profitability index $\lambda_{j} \equiv\left(\alpha_{j}-c_{j}\right)$ and $\psi_{-j}=\psi^{*}$, the first-order condition for manager $j$ 's incentives from (9) can be written more compactly as

$$
s \lambda_{j}-X^{*}-x_{j}^{*}\left(1+\psi^{*}\right)=0 .
$$

In the incentive equilibrium, firm $j$ produces more output than firm $k\left(x_{j}^{*} \geq x_{k}^{*}\right)$ if and only if it has a higher profitability index $\left(\lambda_{j} \geq \lambda_{k}\right)$. So the firm with the highest market share $\sigma_{\max }$ also has the highest profitability index $\lambda_{\max }$. The underlying logic works in reverse too: Firms with higher market shares - as observed empirically - have higher product quality and/or lower unit costs.

Welfare losses in the incentive equilibrium can now be determined using the model's three key components: The welfare function from (4), the equilibrium conditions from (11), and the strategic effect from (10).

Proposition 1 Equilibrium welfare losses

$$
L^{*}\left(n, \sigma_{\max }, H\right)=1-\frac{n(n+2 H)}{\left(n+\sigma_{\max }\right)^{2}},
$$

where $n$ is the number of firms in the industry, $\sigma_{\max }$ is the market share of the largest firm, and $H \equiv \sum_{j=1}^{n} \sigma_{j}^{2}$ is the industry's Herfindahl index.

\footnotetext{
${ }^{14}$ Of course, the crucial difference is that, under delegation, a firm exploits its ability to strategically influence its rivals' output choices, whereas it does not do so in a standard Cournot equilibrium (by construction, as this is a one-stage setting).
} 
Proof. Summing the $n$ first-order conditions from (11) and rearranging yields equilibrium industry output

$$
X^{*}=\frac{s \sum_{j=1}^{n} \lambda_{j}}{\left[n+\left(1+\psi^{*}\right)\right]} .
$$

Plugging this back into the first-order condition gives firm $j$ 's equilibrium output

$$
x_{j}^{*}=\frac{\left[s \lambda_{j}\left[n+\left(1+\psi^{*}\right)\right]-s \sum_{j=1}^{n} \lambda_{j}\right]}{\left(1+\psi^{*}\right)\left[n+\left(1+\psi^{*}\right)\right]},
$$

so firm $j$ 's market share

$$
\sigma_{j}=\frac{\left[\lambda_{j}\left[n+\left(1+\psi^{*}\right)\right]-\sum_{j=1}^{n} \lambda_{j}\right]}{\left(1+\psi^{*}\right) \sum_{j=1}^{n} \lambda_{j}} .
$$

Using this, firm $j$ 's profitability index can, in equilibrium, be written as

$$
\lambda_{j}=\frac{\left[1+\left(1+\psi^{*}\right) \sigma_{j}\right] \sum_{j=1}^{n} \lambda_{j}}{\left[n+\left(1+\psi^{*}\right)\right]} .
$$

Now using (12), (13) and (15) in the expression for social welfare from (4) yields

$$
W^{*}=\frac{s}{2}\left(\frac{\sum_{j=1}^{n} \lambda_{j}}{n+\left(1+\psi^{*}\right)}\right)^{2}\left[1+2\left(1+\psi^{*}\right) H\right],
$$

where $H \equiv \sum_{j=1}^{n} \sigma_{j}^{2}$ is the industry's Herfindahl index. From (5), first-best social welfare $W^{F B}=(s / 2) \lambda_{\max }^{2}$, and, using (15),

$$
\lambda_{\max }=\frac{\left[1+\left(1+\psi^{*}\right) \sigma_{\max }\right] \sum_{j=1}^{n} \lambda_{j}}{\left[n+\left(1+\psi^{*}\right)\right]},
$$

SO

$$
W^{F B}=\frac{s}{2}\left(\frac{\sum_{j=1}^{n} \lambda_{j}}{n+\left(1+\psi^{*}\right)}\right)^{2}\left[1+\left(1+\psi^{*}\right) \sigma_{\max }\right]^{2} .
$$

Since, from (10), the strategic effect $\psi^{*}=-\left(1-n^{-1}\right)$, it follows that welfare losses $L=1-W / W^{F B}$, in equilibrium, satisfy

$$
L^{*}\left(n, \sigma_{\max }, H\right)=1-\frac{n(n+2 H)}{\left(n+\sigma_{\max }\right)^{2}},
$$

as claimed. 
Equilibrium welfare losses depend only on three variables: The number of firms in the industry $(n)$, the market share of the largest firm $\left(\sigma_{\max }\right)$, and the Herfindahl index $(H)$. These industry data are often readily available to the analyst, making it straightforward to put the formula into practice and estimate welfare losses for a particular market. For instance, observing the vector of market shares $\left\{\sigma_{1}, \sigma_{2}, \ldots, \sigma_{n}\right\}$ is sufficient to be able to compute welfare losses.

Note also what welfare losses do not depend on:

First, conditional on firms' market shares, welfare losses do not depend on the profitability indices (the $\left.\lambda_{j} \mathrm{~s}\right)$, that is, on product qualities $\left(\alpha_{j} \mathrm{~s}\right)$ or on firms' unit costs (the $\left.c_{j} \mathrm{~s}\right)$;

Second, a change in market size $(s)$ also does not affect the welfare loss. All else equal, a market that is twice as large doubles both first-best and equilibrium social welfare, so their ratio and hence the (percentage) welfare loss are unchanged;

Third, welfare losses also do not depend on the (equilibrium) incentive weights from managers' contacts (the $\left.\theta_{j}^{*} \mathrm{~s}\right) .{ }^{15}$ What matters in equilibrium is only the strategic effect $\psi^{*}$ which in turn depends only on the number of firms in the industry.

Welfare losses are thus independent of (equilibrium) price elasticities of demand.

\section{Symmetric firms}

The properties of the formula for welfare losses are most easily explored by initially examining the case with symmetric firms before turning to the impact of firm asymmetry.

With symmetry, product quality $\alpha_{j}=\alpha$ (so the industry demand curve $p(X)=$ $\alpha-X / s)$ and unit cost $c_{j}=c$ (for all $j$ ), so social welfare $W=\int_{z=0}^{X}\{p(z)-c\} d z$.

Proposition 2 If firms in the industry are symmetric (have identical unit costs and product quality), then equilibrium welfare losses

$$
L_{\text {sym }}^{*}(n)=\frac{1}{\left(n^{2}+1\right)^{2}}
$$

(i) are always less than $4 \%$ (for any $n \geq 2$ );

(ii) are less than $1 \%$ whenever there are at least three firms (if $n \geq 3$ ).

Proof. The formula is obtained by setting $\sigma_{\max }=1 / n$ and $H=1 / n$ in the expression for $L^{*}\left(n, \sigma_{\max }, H\right)$ from Proposition 1 and rearranging terms. Parts (i) and (ii) of the proposition follow by inspection.

\footnotetext{
${ }^{15}$ The equilibrium incentive weight for manager $j$ is easily backed out from the first-order conditions, which imply that $\theta_{j}^{*} c_{j}=\left(x_{j}^{*} / s\right)\left(-\psi^{*}\right)$.
} 
The result shows that delegation of decision-making to managers with strategic incentive contracts has a significant impact on market performance:

In a symmetric duopoly, for example, equilibrium welfare losses are only 4 percent. In other words, 96 percent of the maximum possible social surplus is realized even in a highly concentrated market with only two sellers. With at least three firms, the loss is always than 1 percent, so over 99 percent of maximum welfare is achieved.

By comparison, the welfare loss due to monopoly (by setting $n=1$ ) is large at $L_{\text {sym }}^{*}(1)=25 \%$. So, put differently, the entry of the second firm eliminates 84 percent of the deadweight loss due to imperfect competition, and the entry of the third firm brings this figure up to 96 percent. The social value of these first few entrants is therefore very high.

Amongst other things, this result closely matches the empirical finding of Bresnahan and Reiss (1991) that entry beyond a third firm has virtually no further effect on the competitiveness of a market. ${ }^{16}$ The reason here is that an additional firm not only reduces price due to the standard entry effect, but also intensifies competition indirectly because it enhances the strategic effect of delegation.

As a rule of thumb, welfare losses with symmetry are of order $1 / n^{4}$, and thus vanish extremely quickly. Compared to profit-maximization, $n$ "sales-maximizing" firms under delegation act like $n^{2}$ profit-maximizing firms would under Cournot competition, so the industry is much more competitive.

\section{Asymmetric firms}

Welfare losses are higher when firms are asymmetric. With homogeneous products, for instance, cost efficiency requires all industry output to be produced by the firm with the lowest unit costs. As pointed out by Farrell and Shapiro (1990), Lahiri and Ono (1988) and others, this is typically not the case in Cournot-style markets.

Similarly, with vertically differentiated products - but symmetric costs - maximizing social surplus requires all industry output to be supplied by the firm with the highest-quality product. (Again, the standard Cournot equilibrium is inefficient in that low-quality firms have too large market shares.) More generally, the firm with the highest profitability index $\lambda_{\max }$ would need to supply all output at a price equal to its unit cost.

\footnotetext{
${ }^{16}$ Bresnahan and Reiss (1991) study entry and competition in five retail and professional industries (doctors, dentists, chemists, plumbers, and tire dealers) across 202 geographic markets in the U.S. It seems likely that firm asymmetries are limited within their sample of industries.
} 
With equilibrium incentives, however, an additional efficiency effect arises compared to profit-maximization: Since competition is more intense under delegation, lower-cost/higher-quality firms capture higher market shares than under Cournot competition. Put differently, for a high-cost/low-quality firm to sustain a given market share, its disadvantage relative to other firms must be smaller under delegation. This effect very significantly limits welfare losses due to firm asymmetry.

The following result characterizes the limiting cases.

Proposition 3 Equilibrium welfare losses $L^{*}\left(n, \sigma_{\max }, H\right)$

(i) are bounded above by $14 \frac{2}{7} \%$ for any $n \geq 2$ (where this bound is tight for an asymmetric duopoly with $n=2$ and $\sigma_{\max }=\frac{4}{5}$ );

(ii) are lower than welfare losses due to a monopoly (where $n=1$ );

(iii) tend to zero as the number of firms grows large (as $n \rightarrow \infty)$.

Proof. See the appendix.

The market structure that maximizes welfare losses for Cournot competition (with linear demand) involves a dominant firm with 50 percent market share together with a long tail of small, high-cost firms with infinitesimal market shares (see Corchón, 2008). This constellation leads to a welfare loss of $33 \frac{1}{3}$ percent which even exceeds the deadweight loss of 25 percent due to monopoly. By contrast, with strategic incentives, welfare losses for this market structure are (approximately) zero!

Proposition 3(ii) and 3(iii) show that welfare losses with equilibrium incentives are always lower than for a monopoly, and always tend to zero as the number of firms grows large. The reason is again that more firms increase the scope for strategic manipulation (as the strategic effect $\psi^{*} \rightarrow-1$ ). So the "trick" from Cournot competition of adding a long tail of inefficient firms to generate very high welfare losses does not work. The result thus restores the traditional view that monopoly is the worst possible outcome from a social standpoint — and the intuition that "many firms" is best.

Proposition 3(i) provides a theoretical upper bound on welfare losses in incentive equilibrium of $14 \frac{2}{7}$ percent, while allowing for arbitrary asymmetries in firms' product qualities and unit costs. The bound is tight for an asymmetric duopoly in which the larger firm has a market share of 80 percent. Of course, this upper bound is significantly higher than the deadweight loss with symmetric firms - although it is also still much lower than the monopoly loss of 25 percent.

Welfare losses tend to be highest for an industry with only few players in which firm asymmetry takes a particular form: The leading firm has a large - but not too large - market share and the remaining $n-1$ firms are symmetric. 
To understand why, observe that welfare losses $L^{*}\left(n, \sigma_{\max }, H\right)$ from Proposition 1 are decreasing in the Herfindahl index. Conditional on the number of firms and the largest market share, more concentration is beneficial since it implies greater cost efficiency (and/or a higher average product quality). This means that welfare losses are highest if the $n-1$ non-leading firms have exactly symmetric market shares.

Furthermore, it is clear that a substantial welfare loss requires that the largest firm's market share is well above average. However, a very high $\sigma_{\max }$ also implies reduced allocative inefficiency — since then almost all output is produced by the "strongest" firm (with profitability index $\lambda_{\max }$ ). Specifically, the proof of Proposition 3 shows that the largest market share that maximizes welfare losses $\sigma_{\max }^{\star} \in\left(\frac{3}{7}, \frac{4}{5}\right]$, where 80 percent is for the duopoly case and $\sigma_{\max }^{\star}$ falls to around 43 percent as the number of firms increases.

As a numerical example, consider a four-firm industry in which the observed market shares are $\sigma_{1}=40 \%, \sigma_{2}=30 \%, \sigma_{3}=20 \%$, and $\sigma_{4}=10 \%$. So the largest market share $\sigma_{\max }=40 \%$ and the industry's Herfindahl index $H=30 \%$. This easily qualifies as a "highly concentrated market" according to the guidelines of the U.S. Department of Justice and Federal Trade Commission. ${ }^{17}$ Using the formula from Proposition 1, equilibrium welfare losses $L^{*}=\frac{6}{121}$, or just below 5 percent. By comparison, deadweight losses for this market structure under Cournot competition would be more than three times as large at above 18 percent. ${ }^{18}$

Aghion and Schankerman (2004) note that the typical value of the Herfindahl index averaged across industries is about $10 \%$ for the U.S. and several industrializing countries. Ali, Klasa and Yeung (2009) report an average Herfindahl index of $6.4 \%$ for four-digit SIC industries using the U.S. Census of Manufactures over the period 1982 to 2002 . These figures imply a (very weak) upper bound on $\sigma_{\max }$ of around 25-35\% (since certainly $\sigma_{\max }<\sqrt{H}$ ). Note also that a combined market share of no more than 35 percent for merging firms is often considered to be a "safe harbour" under the 1992 U.S. guidelines (see $§ 2.211$ ).

The following result shows that such an upper bound on $\sigma_{\max }$ is sufficient for equilibrium welfare losses to be "small."

Proposition 4 If the largest firm's market share $\sigma_{\max }$ does not exceed $35 \%$ (with

\footnotetext{
${ }^{17}$ This statement holds under the U.S. Department of Justice's 1992 Horizontal Merger Guidelines (revised in 1997), as well as under the latest revisions to the guidelines that were proposed in April 2010 (and released in August 2010).

${ }^{18}$ For example, using the results from Section 4 of Corchón (2008). More generally, the formulae from the present analysis, in conjunction with those from Anderson and Renault (2003) and Corchón (2008), can be used to compare numerically welfare losses in incentive equilibrium with Cournot competition.
} 
$n \geq 3$ firms), then equilibrium welfare losses $L^{*}\left(n, \sigma_{\max }, H\right)$ are less than approximately $4 \frac{2}{3} \%$.

Proof. See the appendix.

Taken together, the results show that, with equilibrium incentives, welfare losses due to imperfect competition are likely to be small for many empirically relevant market structures - despite significant firm asymmetry and industry concentration. ${ }^{19}$ In particular, welfare losses are bounded above by 5 percent if either (i) firms' unit costs and product qualities are sufficiently similar (Proposition 2), or (ii) if there are sufficiently many firms in the industry (Proposition 3), or (iii) if the largest firm's market share is sufficiently small (Proposition 2 and Proposition 4). Note especially that none of these statements are valid, in general, for Cournot competition with profit-maximizing firms.

\section{Further applications}

Propositions 1 to 4 also apply to strategically equivalent settings with (A) competition between oligopsonists, and (B) strategic forward trading.

(A) Competition between oligopsonists. The above results apply equally to oligopsonistic markets in which managers pursue strategic incentives. For example, bank deposit markets are a natural application in that they often involve localized competition between a relatively small number of banks with largely homogeneous products. Moreover, deposit-taking is one of the core business activities of commercial banks, and there is a strong policy interest in market structure and competition in the banking sector following the 2007-9 financial crisis.

Following Klein (1971), Hannan and Berger (1991) and others, consider the following simple model in which $n \geq 2$ commercial banks compete for customer deposits. Bank $j$ has unit cost $c_{j}$, takes deposit volume $D_{j}$, and has market share $\sigma_{j}=D_{j} / D$ (where $D \equiv \sum_{j=1}^{n} D_{j}$ is total deposits). As above, let $\sigma_{\max } \equiv \max _{j} \sigma_{j}$ denote the highest market share.

On the supply side, consumer (dis-)utility $-U\left(D_{1}, \ldots, D_{n}\right)=\sum_{j=1}^{n} \tau_{j} D_{j}+D^{2} / 2 s$. Letting $r_{j}$ denote bank $j$ 's deposit rate, utility maximization yields an inverse supply curve $r_{j}(D)=\tau_{j}+D / s$ for bank $j$. Suppose further that bank $j$ invests its customers'

\footnotetext{
${ }^{19}$ Numerical calculations also confirm that somewhat larger welfare losses in the double digits are possible only in asymmetric duopoly and triopoly settings where the largest firm's market share is sufficiently close to $\sigma_{\max }^{\star}$.
} 
deposits to yield an expected return $\rho_{j} \cdot{ }^{20}$ Let $\lambda_{j} \equiv\left(\rho_{j}-\tau_{j}-c_{j}\right)>0$ denote a profitability index for bank $j$, and also let $\lambda_{\max } \equiv \max _{j} \lambda_{j}$. All else equal, a bank is more profitable if it has better investment opportunities (higher $\rho_{j}$ ), more favourable deposit supply (lower $\tau_{j}$ ), or lower unit costs (lower $c_{j}$ ).

Banks' shareholders delegate decision-making to their managers, and manager $j$ maximizes $\Omega_{j}=\left(1-\theta_{j}\right) \Pi_{j}+\theta_{j} Y_{j}$, a combination of profits $\Pi_{j}=\left(\rho_{j}-r_{j}-c_{j}\right) D_{j}$ and gross income $Y_{j}=\rho_{j} D_{j}$. Social welfare is the sum of consumer and producer surplus, and can be written as

$$
W\left(D_{1}, \ldots, D_{n}\right)=\sum_{j=1}^{n} \lambda_{j} D_{j}-D^{2} / 2 s .
$$

The key point is that this setting is strategically equivalent to the model of Section 2, with firms' outputs replaced by banks' deposits and a simple reinterpretation of the profitability indices. First-best has the bank with the highest profitability index taking all deposits $D^{F B}=s \lambda_{\max }$ (at an interest rate equal to its own investment rate minus its unit costs), so first-best social welfare $W^{F B}=(s / 2) \lambda_{\max }^{2}$.

Aggressive incentives (with higher $\theta_{j}$ ) here, too, induce parallel, outward shifts in bank manager $j$ 's best response curve as defined by the first-order condition

$$
\frac{\partial \Omega_{j}}{\partial D_{j}}=\left(1-\theta_{j}\right) \frac{\partial \Pi_{j}}{\partial D_{j}}+\theta_{j} \frac{\partial Y_{j}}{\partial D_{j}}=0
$$

Let $D_{j}^{*}\left(\theta_{1}, \ldots, \theta_{n}\right)$ denote manager $j$ 's equilibrium deposit choice as a function of all managers' incentive weights. As above, these first-order conditions also determine the strategic effect $\psi_{-j} \equiv d D_{-j} / d D_{j}$ (where $D_{-j}=\sum_{k \neq j} D_{k}$ ). Given this, the shareholders of bank $j$ choose their manager's incentives according to

$$
\frac{d \Pi_{j}^{*}}{d \theta_{j}}=\left[\left(\rho_{j}-r_{j}\left(D^{*}\right)-c_{j}\right)-r_{j}^{\prime}\left(D^{*}\right) D_{j}^{*}\left(1+\psi_{-j}\right)\right] \frac{d D_{j}^{*}}{d \theta_{j}}=0,
$$

where $d D_{j}^{*} / d \theta_{j}>0$. With the linear supply structure, it is easy to check that $\psi_{-j}=$ $-\left(1-n^{-1}\right) \equiv \psi^{*}$, so competition between banks is again in strategic substitutes. Using the profitability index $\lambda_{j} \equiv\left(\rho_{j}-\tau_{j}-c_{j}\right)$ and $\psi_{-j}=\psi^{*}$, the first-order condition from $(22)$ can be rewritten as

$$
s \lambda_{j}-D^{*}-D_{j}^{*}\left(1+\psi^{*}\right)=0 .
$$

Observe that this equilibrium condition, the welfare function, and the strategic

\footnotetext{
${ }^{20}$ These investments could represent a combination of interbank market loans to other financial institutions and the portfolio of securities held on the balance sheet. For simplicity, the model focuses on welfare losses in the deposit market, without explicitly accounting for other markets.
} 
effect are all equivalent to the previous analysis. Thus, the formula for welfare losses from Proposition 1 also applies to this model, as do Propositions 2 to 4. With strategic incentives, therefore, welfare losses due to oligopsony are less than 5 percent under the conditions previously identified.

(B) Strategic forward trading. The above propositions also apply to the seminal model of strategic forward trading due to Allaz and Vila (1993). In contrast to above, firms are assumed to be profit-maximizers, but there is scope for strategic commitment via positions taken in the forward market. The impact of forward trading on market performance has recently received much attention, particularly in restructured electricity markets. For example, Bushnell et al. (2008) find that a Cournot model augmented with forward contracting commitments performs well in simulations of market outcomes in three restructured U.S. electricity markets. ${ }^{21}$

In the first period of Allaz and Vila (1993), firms can buy or sell contracts in the forward market for delivery of a good. In the second period, firms produce under Cournot competition in the spot market, given the forward market positions previously entered into. The forward market is efficient with the no-arbitrage condition that, in equilibrium, the forward price equals the spot price. ${ }^{22}$

Their model can be cast into the above framework as follows. The industry parameters are exactly as in Section 2, while firms produce a homogeneous good facing a linear inverse demand curve $p(X)=\alpha-X / s$. Social welfare is the sum of consumer and producer surplus $W\left(x_{1}, \ldots, x_{n}\right)=\sum_{j=1}^{n} \lambda_{j} x_{j}-X^{2} / 2 s$, with $\lambda_{j} \equiv$ $\left(\alpha-c_{j}\right)>0$ as the profitability index for firm $j$. (This generalizes Allaz and Vila's (1993) model to $n \geq 2$ firms and asymmetric unit costs. ${ }^{23}$ )

Let $y_{j}$ denote firm $j$ 's sales in the forward market, and let $p^{F}$ denote the forward price. In the second period, given its forward market position $y_{j}$, firm $j$ maximizes the objective function

$$
\Omega_{j}=p\left(x_{j}-y_{j}\right)-c_{j} x_{j},
$$

since revenue accrues only on the $\left(x_{j}-y_{j}\right)$ non-committed units of production. The

\footnotetext{
${ }^{21}$ Bushnell et al. (2008) analyze a model in which electricity firms compete in both a wholesale spot market and a retail market, and firms' retail positions play a formally identical role to longterm forward commitments.

${ }^{22}$ Forward contracts are assumed to be binding and observable, and there is no discounting. Note also that speculators make zero profits in the no-arbitrage equilibrium.

${ }^{23}$ Allaz and Vila (1993) do not incorporate capacity constraints, which may exacerbate firms' market power. Conversely, they show that additional periods of forward contracting magnify the strategic effect, so welfare losses will generally be even lower in such cases.
} 
associated first-order condition

$$
\frac{\partial \Omega_{j}}{\partial x_{j}}=p(X)-c_{j}+p^{\prime}(X)\left(x_{j}-y_{j}\right)=0
$$

implicitly defines firm $j$ 's best response in the spot market. Let $x_{j}^{*}\left(y_{1}, \ldots, y_{n}\right)$ denote its output choice as a function of all forward positions. These first-order conditions again determine the strategic effect $\psi_{-j} \equiv d X_{-j} / d x_{j}$ (where $X_{-j}=\sum_{k \neq j} x_{k}$ ). With linear demand, $\psi_{-j}=-\left(1-n^{-1}\right) \equiv \psi^{*}$, so competition is in strategic substitutes, exactly as above.

In the first period, firm $j$ 's total profits are given by

$$
\Pi_{j}=\left(p-c_{j}\right) x_{j}+y_{j}\left(p^{F}-p\right)
$$

where the first term reflects operating profits, and the second term reflects forwardmarket profits. In equilibrium, the latter term is zero with an efficient forward market (for which $p^{F}=p$ ). So firm $j$ 's equilibrium profits $\Pi_{j}^{*}=\left(p-c_{j}\right) x_{j}^{*}$, and it chooses its forward market position according to

$$
\frac{d \Pi_{j}^{*}}{d y_{j}}=\left[p\left(X^{*}\right)-c_{j}+p^{\prime}\left(X^{*}\right) x_{j}^{*}\left(1+\psi_{-j}\right)\right] \frac{d x_{j}^{*}}{d y_{j}}=0,
$$

where $d x_{j}^{*} / d y_{j}>0$ (so more forward sales make firm $j$ more aggressive in the spot market). Using the profitability index $\lambda_{j} \equiv\left(\alpha-c_{j}\right)$ and $\psi_{-j}=\psi^{*}$, this first-order condition can be written as

$$
s \lambda_{j}-X^{*}-x_{j}^{*}\left(1+\psi^{*}\right)=0 .
$$

This shows that Allaz and Vila's (1993) two-period forward trading model is also strategically equivalent to the model of Section 2. Although forward contracts may seem quite different from managerial incentives, they here induce exactly the same product-market outcomes because they share the same underlying strategic properties.

Of course, it is well-known that forward sales make competition between firms more aggressive and improve market performance. However, much of the existing empirical literature on deregulated electricity markets focuses on estimating pricecost margins (Lerner indices) as a proxy for welfare losses due to market power. Propositions 1 to 4 go further by directly quantifying the welfare impact and showing that equilibrium welfare losses under forward trading are less than 5 percent under the conditions previously identified. 
The framework presented in this paper also clarifies the extent to which firms engage in strategic forward trading. In particular, combining the two first-order conditions from (25) and (27), and setting $\psi_{-j}=\psi^{*}$, shows that firm $j$ 's equilibrium forward market position satisfies

$$
y_{j}^{*}=\left(-\psi^{*}\right) x_{j}^{*}
$$

Thus, in the subgame-perfect equilibrium, each firm sells forward the same proportion of its output. Since $-\psi^{*} \in\left[\frac{1}{2}, 1\right)$ for any $n \geq 2$, this proportion lies between 50 percent (for a duopoly) and 100 percent (as the number of firms grows large). ${ }^{24}$ This finding is broadly consistent with restructured electricity markets in which contract cover is often 80 percent or more (see, e.g., Green, 1999 and Sweeting, 2007).

\section{Extensions}

This section discusses three extensions of the benchmark model from Section 2 . First, on the demand side, a consumer utility function that leads to non-linear demand curves. Second, on the supply side, a fixed setup cost incurred by firms that have entered the market. Third, some general results on welfare losses that apply with non-linear demand, fixed setup costs, and a generalized welfare function.

To my best knowledge, this section provides the first solution to a model of strategic incentives with asymmetric firms and a non-linear demand system. The three extensions draw upon formulae contained in the proof of Proposition 5 in the appendix (which contains a full set of derivations for the general model).

Consistent with the benchmark model, this section considers situations where the vector of firms' market shares is observed by the analyst - and thus is invariant to changes in the details of model specification. For example, although a change in demand curvature will generally lead to changes in firms' implied (yet unobserved) profitability indices — and also in equilibrium welfare losses — it does not alter firms' observed market shares (or the observed number of firms in the industry). ${ }^{25}$

\footnotetext{
${ }^{24}$ This also makes clear that firms would become forward buyers in a setting with competition in strategic complements (that is, $\psi^{*}>0$ ). See also Mahenc and Salanié (2004) who make a related point in a model of differentiated-products Bertrand competition.

${ }^{25}$ This contrasts with the usual theoretical approach of initially specifying firms' demands and costs, and then deriving equilibrium entry, market shares, prices, welfare, and so on, for a particular model of competition. Instead, with a view to empirical implementation, my approach starts with the observed number of firms and their market shares, then implicitly works "backwards" to find the implied profitability indices, and thus calculates equilibrium welfare losses.

My approach therefore also allows comparisons between equilibria with strategic incentives and standard Cournot competition for a given, empirically observed, market structure.
} 


\section{A Non-linear demand}

Consider the benchmark model from Section 2 with a more general consumer utility function

$$
U\left(x_{1}, \ldots, x_{n}\right)=\sum_{j=1}^{n} \alpha_{j} x_{j}-X^{\gamma+1} /(\gamma+1) s,
$$

so the inverse demand curve for firm $j$ becomes

$$
p_{j}(X)=\alpha_{j}-X^{\gamma} / s .
$$

As before, $\alpha_{j}$ is a measure of demand for firm $j$ 's product (e.g., its quality) and $s>0$ is a measure of market size. In addition, $\gamma$ is an index of demand curvature: Demand is convex (concave) if $\gamma \leq 1(\gamma \geq 1)$, and higher values of $\gamma$ correspond to "more concave" demand.

Many familiar demand curves are nested as special cases of this formulation. For example, it includes all four demand specifications used by Genesove and Mullin (1998) in an influential empirical study of the U.S. sugar industry. In particular, demand (i) is linear if $\gamma=1$, (ii) is quadratic if $\gamma=\frac{1}{2}$, (iii) is exponential in the limit as $\gamma \rightarrow 0$ (for which $p_{j}(X)=\alpha_{j}-\log (X) / s$ ), and (iv) has constant elasticity of $-1 / \gamma>0$ if $\alpha_{j}=0$ (for all $j$ ) and $s<0 .{ }^{26}$

Demand is not too convex in that $\gamma>-\sigma_{j} /\left(1-\sigma_{j}\right)$ (for $j=1,2$ with $\left.n=2\right)$, and $\gamma>-1$ for $n \geq 3$. These assumptions are necessary and sufficient for competition between firms to be in strategic substitutes (i.e., the strategic effect $\psi_{-j}<0$ for all $j$ ) for any distribution of firms' market shares. They also ensure that consumer surplus $S=U\left(x_{1}, \ldots, x_{n}\right)-\sum_{j=1}^{n} p_{j} x_{j}$ is well-behaved and finite.

Social welfare, the sum of consumer surplus and producer surplus, is given by

$$
W\left(x_{1}, \ldots, x_{n}\right)=\sum_{j=1}^{n} \lambda_{j} x_{j}-X^{\gamma+1} /(\gamma+1) s .
$$

So first-best social welfare involves industry output $X^{F B}=\left(s \lambda_{\max }\right)^{1 / \gamma}$ and thus

$$
W^{F B}=\frac{\gamma}{(\gamma+1)} s^{1 / \gamma} \lambda_{\max }^{(\gamma+1) / \gamma}
$$

Observe that the two first-order conditions from (7) and (9) in Section 3 are valid also for non-linear demand. Using the first-order condition for manager $j$ 's output

\footnotetext{
${ }^{26}$ Genesove and Mullin (1998) focus on the case with homogenenous products (that is, $\alpha_{j}=\alpha$ ). Their approach has been employed and extended in various papers, including recently in empirical work by Clay and Troesken (2003) and applied theory by Verboven and van Dijk (2009).
} 
choice, $\partial \Omega_{j} / \partial x_{j}=0$, it is straightforward to calculate the generalized strategic effect

$$
\frac{d X_{-j}}{d x_{j}}=-\left[\frac{(n-1)-\left(1-\sigma_{j}\right)(1-\gamma)}{n-\left(1-\sigma_{j}\right)(1-\gamma)}\right] \equiv \psi_{-j}<0 .
$$

With non-linear demand, therefore, the strategic effect differs across firms (so $\psi_{-j} \neq$ $\psi_{-k}$ for $j \neq k$ ); it is more negative for larger (smaller) firms if demand is concave (convex). Note that, in general, $\psi_{-j}$ is more negative for a more concave demand curve (that is, $\psi_{-j}$ declines as $\gamma$ increases). Moreover, the strategic effect $\psi_{-j} \rightarrow-1$ either if the number of firms grows large, $n \rightarrow \infty$ (as in the benchmark model), or if demand becomes very concave, $\gamma \rightarrow \infty$.

The first-order condition for firm $j$ 's choice of incentives, $d \Pi_{j}^{*} / d \theta_{j}=0$, can be written as

$$
s \lambda_{j}-\left(X^{*}\right)^{\gamma}\left[1+\gamma \sigma_{j}\left(1+\psi_{-j}\right)\right]=0 .
$$

Welfare losses can again be determined using the model's three key components: The welfare function from (32), the equilibrium conditions from (35), and the strategic effects from (34).

Symmetric firms. The formula for welfare losses is again relatively simple if firms are symmetric in terms of their unit costs and product qualities,

$$
L_{\mathrm{sym}}^{*}(n, \gamma)=1-\frac{\left[1+\frac{(\gamma+1)}{n^{2}-(n-1)(1-\gamma)}\right]}{\left[1+\frac{\gamma}{n^{2}-(n-1)(1-\gamma)}\right]^{(\gamma+1) / \gamma}}
$$

Table 1 presents numerical results for a variety of demand specifications, including the four used by Genesove and Mullin (1998). The two most convex demand curves are those with constant elasticity, one as the limiting case with unit-elasticity $(\gamma \rightarrow-1)$ and the other with a price elasticity of two $\left(\gamma=-\frac{1}{2}\right)$. The next three demand curves, exponential $(\gamma \rightarrow 0)$, quadratic $\left(\gamma=\frac{1}{2}\right)$, and linear $(\gamma=1)$, are all convex (at least weakly). Finally, I also present welfare losses for three strictly concave demand curves: Two moderately concave demand curves $(\gamma=2$ and $\gamma=3)$, as well as the limiting case where demand becomes rectangular $(\gamma \rightarrow \infty)$.

These results are quantitatively similar to those for the linear case from Proposition 2 (with $\gamma=1$ ), while allowing for a much more general class of demand functions. It turns out that welfare losses are maximized at approximately $4 \frac{1}{2}$ percent for a duopoly with exponential demand (that is, $n=2$ and $\gamma \rightarrow 0$ ). They are less than approximately 1 percent for any industry with three or more symmetric firms. 
As expected, market performance improves as the number of firms increases, and it is clear that the rule of thumb that symmetric welfare losses are of order $1 / n^{4}$ is robust to different demand specifications.

With symmetric firms, equilibrium welfare losses are therefore bounded above by 5 percent for any number of firms and any demand curvature. Moreover, they tend to zero under any of the following conditions: (i) The number of firms grows large (as $n \rightarrow \infty$ ), or (ii) demand becomes very convex (as $\gamma \rightarrow-1$ ), or (iii) demand becomes very concave (as $\gamma \rightarrow \infty$ ).

Table 1: Equilibrium welfare losses (in percent) with symmetric firms

\begin{tabular}{ccccccccc}
\hline \hline & \multicolumn{8}{c}{ Demand curvature $(\gamma)$} \\
\cline { 2 - 9 } $\begin{array}{c}\text { Number of } \\
\text { firms }(n)\end{array}$ & -1 & $-\frac{1}{2}$ & 0 & $\frac{1}{2}$ & 1 & 2 & 3 & $\infty$ \\
\hline 2 & 0.00 & 4.00 & 4.46 & 4.30 & 4.00 & 3.41 & 2.94 & 0.00 \\
3 & 0.00 & 0.69 & 0.93 & 1.00 & 1.00 & 0.94 & 0.86 & 0.00 \\
4 & 0.00 & 0.19 & 0.28 & 0.33 & 0.35 & 0.35 & 0.34 & 0.00 \\
5 & 0.00 & 0.07 & 0.11 & 0.13 & 0.15 & 0.16 & 0.16 & 0.00 \\
6 & 0.00 & 0.03 & 0.05 & 0.06 & 0.07 & 0.08 & 0.09 & 0.00 \\
7 & 0.00 & 0.02 & 0.03 & 0.03 & 0.04 & 0.05 & 0.05 & 0.00 \\
8 & 0.00 & 0.01 & 0.02 & 0.02 & 0.02 & 0.03 & 0.03 & 0.00 \\
9 & 0.00 & 0.01 & 0.01 & 0.01 & 0.01 & 0.02 & 0.02 & 0.00 \\
10 & 0.00 & 0.00 & 0.01 & 0.01 & 0.01 & 0.01 & 0.01 & 0.00 \\
20 & 0.00 & 0.00 & 0.00 & 0.00 & 0.00 & 0.00 & 0.00 & 0.00 \\
$\infty$ & 0.00 & 0.00 & 0.00 & 0.00 & 0.00 & 0.00 & 0.00 & 0.00 \\
\hline \hline
\end{tabular}

Asymmetric firms. Welfare losses can again be significantly higher when firms are asymmetric. In particular, with non-linear demand, equilibrium welfare losses

$$
L^{*}\left(n, \sigma_{\max }, \widetilde{H}, \gamma\right)=1-\frac{\left[1+(\gamma+1) \frac{\widetilde{H}}{n}\right]}{\left[1+\frac{\gamma \sigma_{\max }}{n-\left(1-\sigma_{\max }\right)(1-\gamma)}\right]^{(\gamma+1) / \gamma}},
$$

where

$$
\widetilde{H} \equiv \sum_{j=1}^{n}\left\{\frac{n \sigma_{j}^{2}}{n-\left(1-\sigma_{j}\right)(1-\gamma)}\right\}
$$

is the industry's adjusted Herfindahl index. ${ }^{27}$

\footnotetext{
${ }^{27}$ Note that $\widetilde{H}=\sum_{j=1}^{n} \sigma_{j}^{2} \equiv H$ if firms' demand curves are linear (with $\gamma=1$ ).
} 
With non-linear demand, welfare losses again depend on the number of firms in the market $(n)$ and the largest firm's market share $\left(\sigma_{\max }\right)$. However, they now also depend on demand curvature $(\gamma)$, as well as on the entire vector of market shares, $\left\{\sigma_{1}, \sigma_{2}, \ldots, \sigma_{n}\right\}$. In contrast to the case with linear demand, the standard Herfindahl index is no longer a sufficient statistic for the distribution of market shares. ${ }^{28}$

By inspection, welfare losses tend to zero as (i) the number of firms grows large (as $n \rightarrow \infty$ ) or (ii) demand becomes very convex (as $\gamma \rightarrow-1$ ). The first point confirms the basic insight from the benchmark model that "many firms" leads to the socially optimal outcome in a setting with strategic incentives. The second point is important because it shows that, despite firm asymmetries, welfare losses with a convex demand curve must — at least in some cases - be smaller than they are for linear demand.

Observe that equilibrium welfare $\operatorname{losses} L^{*}\left(n, \sigma_{\max }, \gamma, \widetilde{H}\right)$ with non-linear demand are decreasing in the adjusted Herfindahl index, $\widetilde{H}$. As with linear demand, therefore, higher concentration is beneficial as it implies greater efficiency (conditional on the number of firms and the largest firm's market share) ${ }^{29}$ So welfare losses are again highest if the $n-1$ non-leading firms have exactly symmetric market shares.

Table 2 thus explores the impact of demand curvature using numerical results for an industry in which the largest firm has a market share of 35 percent and the remaining firms are symmetric. Further numerical calculations confirm that, as expected, these are maximal welfare losses - losses are always lower than in Table 2 if the largest firm's market share is less than 35\% (for a given number of firms).

These results show that the 5 percent upper bound on welfare losses extends well beyond the benchmark case with linear demand. In particular, maximal welfare losses are uniformly lower than this for any convex demand curve (with $\gamma \leq 1$ ) and also for very slightly concave demand $(\gamma \gtrsim 1)$. So the bound applies to all four demand specifications considered by Genesove and Mullin (1998). These numerical results thus extend Proposition 4 from the benchmark model to settings with nonlinear demand curves.

\footnotetext{
${ }^{28}$ The reason is that the strategic effect $\psi_{-j}$ varies across firms, so each individual firm's characteristics now play a role in determining the equilibrium level of industry output.

${ }^{29}$ The adjusted Herfindahl index shares the property that it is increasing and convex in individual firm's market shares with the standard Herfindahl index. In particular, straightforward calculations show that

$$
\frac{\partial \widetilde{H}}{\partial \sigma_{j}}=n \sum_{j=1}^{n}\left\{\frac{2 \sigma_{j}[n-(1-\gamma)]+(1-\gamma) \sigma_{j}^{2}}{\left[n-\left(1-\sigma_{j}\right)(1-\gamma)\right]^{2}}\right\}>0
$$
}

and

$$
\frac{\partial^{2} \widetilde{H}}{\partial \sigma_{j}^{2}}=2 n \sum_{j=1}^{n}\left\{\frac{[n-(1-\gamma)]^{2}}{\left[n-\left(1-\sigma_{j}\right)(1-\gamma)\right]^{3}}\right\}>0 .
$$


Welfare losses are partially above this bound for the two moderately concave demand curves $(\gamma=2$ and $\gamma=3$ ), for which welfare losses range approximately from 2 percent to 7 percent for the most relevant numbers of firms. (It is worth recalling that these are maximal welfare losses; any asymmetry among smaller firms implies smaller losses.)

Table 2 also shows that it is possible for welfare losses with asymmetric firms to be much higher if firms' demand curves are strongly concave. In such cases, welfare losses are in the double digits for a wide range of market structures, and may be as high as in the low 20s. However, it is somewhat difficult to judge the empirical relevance of these cases as such demand specifications - although theoretically admissible - are only very rarely used in applied work. ${ }^{30}$

Table 2: Maximal equilibrium welfare losses (in percent) with $\sigma_{\max } \leq 35 \%$

\begin{tabular}{ccccccccc}
\hline \hline & \multicolumn{8}{c}{ Demand curvature $(\gamma)$} \\
\cline { 2 - 9 } $\begin{array}{c}\text { Number of } \\
\text { firms }(n)\end{array}$ & -1 & $-\frac{1}{2}$ & 0 & $\frac{1}{2}$ & 1 & 2 & 3 & $\infty$ \\
\hline 3 & 0.00 & 1.02 & 1.52 & 1.79 & 1.96 & 2.15 & 2.24 & 2.41 \\
4 & 0.00 & 1.53 & 2.68 & 3.59 & 4.31 & 5.41 & 6.20 & 11.06 \\
5 & 0.00 & 1.54 & 2.79 & 3.82 & 4.69 & 6.06 & 7.09 & 14.55 \\
6 & 0.00 & 1.44 & 2.65 & 3.67 & 4.56 & 6.01 & 7.14 & 16.44 \\
7 & 0.00 & 1.31 & 2.45 & 3.43 & 4.30 & 5.75 & 6.91 & 17.62 \\
8 & 0.00 & 1.20 & 2.25 & 3.18 & 4.01 & 5.43 & 6.59 & 18.43 \\
9 & 0.00 & 1.10 & 2.07 & 2.95 & 3.74 & 5.10 & 6.25 & 19.01 \\
10 & 0.00 & 1.01 & 1.91 & 2.74 & 3.49 & 4.80 & 5.91 & 19.46 \\
20 & 0.00 & 0.54 & 1.06 & 1.55 & 2.01 & 2.88 & 3.68 & 21.25 \\
$\infty$ & 0.00 & 0.00 & 0.00 & 0.00 & 0.00 & 0.00 & 0.00 & 0.00 \\
\hline \hline
\end{tabular}

In sum, for demand curves commonly used in empirical work, equilibrium welfare losses are typically similar to - or often lower than — welfare losses with linear demand. With symmetric firms, the rule of thumb that welfare losses are of order $1 / n^{4}$ applies generally. The 5 percent upper bound on welfare losses also extends well beyond the linear case. However, welfare losses may be significantly higher in situations where firms' demand curves are sufficiently concave and there is a particular kind of asymmetry in their market shares.

\footnotetext{
${ }^{30}$ In principle, demand curvature can be estimated using non-linear regression techniques as long as sufficiently rich data on prices and quantities are available. However, I am not aware of any empirical work in industrial organization that attempts to estimate curvature directly.
} 


\section{B Fixed entry costs}

Consider the benchmark model from Section 2 but now suppose that each firm incurs a fixed setup cost $K$ whenever it has entered the market. Firms are symmetric in terms of unit costs and product qualities, and the demand curve $p(X)=\alpha-X / s$ is linear. There is a large pool of potential entrants, and an active firm $j$ 's profits $\Pi_{j}=(p-c) x_{j}-K$.

Social welfare, the sum of consumer surplus and producer surplus, becomes $W(X)=X(\lambda-X / 2 s)-n K$, where $\lambda \equiv(\alpha-c)$. The first-best outcome involves a single firm entering the market, and producing industry output $X^{F B}=s \lambda$. So first-best social welfare $W^{F B}=(s / 2) \lambda^{2}-K$, where the setup cost is assumed to be sufficiently low to allow welfare-enhancing entry of at least one firm, $K<(s / 2) \lambda^{2}$.

Observe that the strategic effect and the equilibrium conditions from the benchmark analysis in Section 3 also continue to apply in this setting. ${ }^{31}$ The formula for welfare losses therefore only has to take into account the adverse impact associated with the duplication of fixed costs,

$$
L^{*}(n, K)=\frac{\frac{1}{\left(n^{2}+1\right)^{2}}+(n-1) \frac{K}{(s / 2) \lambda^{2}}}{\left(1-\frac{K}{(s / 2) \lambda^{2}}\right)} .
$$

As expected, the result from Proposition 2 is nested for zero setup costs $(K=0)$, and welfare losses are increasing in the setup cost.

The main complication is that $K$ is typically not easily observable to the analyst. However, with symmetric firms, it is possible to derive upper and lower bounds based on firms' entry decisions. In particular, the equilibrium profits of a symmetric firm are given by

$$
\Pi^{*}(n)=\frac{n}{\left(n^{2}+1\right)^{2}} s \lambda^{2}-K
$$

and since the $n^{\text {th }}$ firm has chosen to enter the market,

$$
\Pi^{*}(n) \geq 0 \Leftrightarrow K \leq \frac{2 n}{\left(n^{2}+1\right)^{2}}(s / 2) \lambda^{2} \equiv \bar{K} .
$$

Slightly abusing notation, firm $(n+1)$ 's decision not to enter implies that

$$
\Pi^{*}(n+1)<0 \Leftrightarrow K>\frac{2(n+1)}{\left[(n+1)^{2}+1\right]^{2}}(s / 2) \lambda^{2} \equiv \underline{K},
$$

\footnotetext{
${ }^{31}$ For a given number of firms in the market, the entry cost has no effect on the equilibrium outcome in terms of prices and quantities.
} 
so welfare losses in free-entry equilibrium $L^{*}(n, K)$ are bounded according to

$$
L^{*}(n, \underline{K})<L^{*}(n, K) \leq L^{*}(n, \bar{K}) .
$$

Table 3 presents numerical calculations, including for $K=0$ as comparison.

Table 3: Welfare losses (in percent) in free-entry equilibrium with setup cost $K$

\begin{tabular}{cccc}
\hline \hline $\begin{array}{c}\text { Number of } \\
\text { firms }(n)\end{array}$ & $\begin{array}{c}\text { Zero setup cost } \\
(K=0)\end{array}$ & $\begin{array}{c}\text { Minimum } K \\
(K=\underline{K})\end{array}$ & $\begin{array}{c}\text { Maximum } K \\
(K=\bar{K})\end{array}$ \\
\hline 2 & 4.00 & 10.64 & 23.81 \\
3 & 1.00 & 6.72 & 13.83 \\
4 & 0.35 & 4.86 & 8.90 \\
5 & 0.15 & 3.69 & 6.16 \\
6 & 0.07 & 2.89 & 4.50 \\
7 & 0.04 & 2.32 & 3.42 \\
8 & 0.02 & 1.90 & 2.68 \\
9 & 0.01 & 1.59 & 2.16 \\
10 & 0.01 & 1.34 & 1.78 \\
20 & 0.00 & 0.41 & 0.47 \\
$\infty$ & 0.00 & 0.00 & 0.00 \\
\hline \hline
\end{tabular}

Welfare losses can be significantly higher if firms incur fixed setup costs. The maximal welfare loss is in the double digits for duopoly and triopoly models, and, with a small number of firms, is roughly twice as large as the minimal loss.

Nonetheless welfare losses remain below 5 percent for many market structures; this upper bound applies to minimal losses $L^{*}(n, \underline{K})$ for $n \geq 4$, and to maximal losses $L^{*}(n, \bar{K})$ for $n \geq 6$. This contrasts sharply with standard Cournot competition, for which the range of possible welfare losses with $n=6$ is given by 18.2 to 23.4 percent, and for which the number of firms needed for welfare losses to be less than 5 percent in free-entry equilibrium is $n \geq 38 .{ }^{32}$

Of course, the notion of first-best is stronger with a setup cost than in the benchmark model. First, the regulator is assumed to control firms' pricing behaviour as well as their entry behaviour. Second, the single producing firm now has negative operating profits (since price lies below average cost). So it is implicit that the regulator can compensate the firm with a transfer payment - but without creating any additional distortions or inefficiency.

\footnotetext{
${ }^{32}$ For example, using the results from Section 3 of Corchón (2008).
} 
Moreover, although standard in the literature (see, e.g., Mankiw and Whinston, 1986, and Corchón, 2008), it is clear that the assumption that firms are completely symmetric (in terms of marginal cost, product quality, and fixed cost) is rather strong. As emphasized by Vickers (1995), this symmetry assumption deprives competition of one of its most basic functions - selecting the most efficient firms. It also means that these models cannot replicate an observed distribution of firms' market shares $\left\{\sigma_{1}, \sigma_{2}, \ldots, \sigma_{n}\right\}$ that almost certainly involves asymmetries.

A richer model allows for heterogenous unit costs and product qualities, while retaining the assumption that the fixed cost is identical across firms, so first-best welfare $W^{F B}=(s / 2) \lambda_{\max }^{2}-K$. The maximum setup cost $\bar{K}$ is pinned down by the firm with the smallest market share, $\sigma_{\min } \equiv \min _{j} \sigma_{j}<n^{-1}$, which also makes the smallest profit,

$$
\Pi_{\min }^{*}=\min _{j} \Pi_{j}^{*}=(s / 2) \lambda_{\max }^{2} \frac{2 n \sigma_{\min }^{2}}{\left(n+\sigma_{\max }\right)^{2}}-K .
$$

Since this firm has decided to enter the market,

$$
\Pi_{\min }^{*} \geq 0 \Leftrightarrow K \leq \frac{2 n \sigma_{\min }^{2}}{\left(n+\sigma_{\max }\right)^{2}}(s / 2) \lambda_{\max }^{2} \equiv \bar{K} .
$$

The key observation is that the maximum entry cost $\bar{K}$ is of the order of $\sigma_{\min }^{2}$. So the market presence of a firm with a "small" market share - even as high as 5 or 10 percent - implies a rather low value for $\bar{K}$. This in turn means that welfare losses are not much above those from the benchmark analysis with a zero entry cost. ${ }^{33}$

Using the last expression for $\bar{K}$ shows that equilibrium welfare losses with asymmetric firms and a fixed setup cost are thus bounded by

$$
L^{*} \leq 1-\frac{n\left[(n+2 H)-2 n \sigma_{\min }^{2}\right]}{\left[\left(n+\sigma_{\max }\right)^{2}-2 n \sigma_{\min }^{2}\right]} \equiv L^{*}\left(n, \sigma_{\max }, \sigma_{\min }, H\right) \text {. }
$$

So Proposition 4 also applies, with slight modifications, to the case with fixed entry costs. In particular, welfare losses are below 5 percent if the largest firm's market share is no greater than 35 percent and (i) the smallest firm's market share is sufficiently small or (ii) the number of firms in the industry is sufficiently large.

In sum, fixed costs generally increase equilibrium welfare losses, possibly by a significant amount. With symmetric firms, the 5 percent upper bound on welfare losses still applies in free-entry equilibrium if there are at least four to six firms in

\footnotetext{
${ }^{33}$ Without symmetry, it is not possible to infer a minimum fixed entry cost in the absence of additional information on the characteristics of firms that have chosen not to enter the market.
} 
the market. With asymmetric firms, the impact of the setup cost remains modest essentially if the smallest firm in the industry is sufficiently small.

\section{General results}

This last extension considers a more general model that combines the features of the two preceding extensions. On the demand side, the consumer utility function from (30) yields a non-linear demand curve $p_{j}(X)=\alpha_{j}-X^{\gamma} / s$ for firm $j$. On the supply side, firm $j$ has profitability index $\lambda_{j} \equiv\left(\alpha_{j}-c_{j}\right)$, and profits $\Pi_{j}=\left(p_{j}-c_{j}\right) x_{j}-K$ (with equilibrium profits $\Pi_{j}^{*} \geq 0$ ).

The generalized welfare function

$$
\widehat{W}(\delta)=S+\delta \sum_{j=1}^{n} \Pi_{j}
$$

where $S$ is consumer surplus, and $\delta \in[0,1]$ is the weight placed on producer surplus. A total surplus standard, as in the above analysis, corresponds to $\delta=1$; a consumer welfare standard is given by $\delta=0$. The generalized welfare loss is defined as

$$
\widehat{L}(\delta)=1-\widehat{W}(\delta) / W^{F B}
$$

I continue to associate the first-best outcome with the firm with highest profitability index $\lambda_{\max }$ producing where $p_{j}\left(X^{F B}\right)=c_{j}$, and so

$$
W^{F B}=\frac{\gamma}{(\gamma+1)} s^{1 / \gamma} \lambda_{\max }^{(\gamma+1) / \gamma}-K
$$

Again, the setup cost is sufficiently low that $W^{F B}=\left(S^{F B}-K\right)>0$, where $S^{F B}$ is the first-best consumer surplus.

Note that the equilibrium conditions and strategic effects derived in Extension A for non-linear demand also apply in this generalized setup.

Proposition 5 Generalized equilibrium welfare losses

$$
\widehat{L}^{*}\left(n, \sigma_{\max }, \widetilde{H}, \gamma, K / S^{*}, \delta\right)=1-\frac{1+\delta\left[(\gamma+1) \frac{\widetilde{H}}{n}-n \frac{K}{S^{*}}\right]}{\left[1+\frac{\gamma \sigma_{\max }}{n-\left(1-\sigma_{\max }\right)(1-\gamma)}\right]^{(\gamma+1) / \gamma}-\frac{K}{S^{*}}},
$$

where

$$
\widetilde{H} \equiv \sum_{j=1}^{n}\left\{\frac{n \sigma_{j}^{2}}{n-\left(1-\sigma_{j}\right)(1-\gamma)}\right\}
$$


is the industry's adjusted Herfindahl index, and

$$
S^{*}=\frac{\gamma}{(\gamma+1)} s^{1 / \gamma}\left[\frac{\sum_{j=1}^{n} \lambda_{j}}{n+\sum_{j=1}^{n}\left\{\frac{\gamma \sigma_{j}}{n-\left(1-\sigma_{j}\right)(1-\gamma)}\right\}}\right]^{(\gamma+1) / \gamma}
$$

is equilibrium consumer surplus.

Proof. See the appendix.

(The formulae for equilibrium welfare losses used in Extensions A and B are nested as special cases of Proposition 5.)

Unsurprisingly, the informational requirements for estimating welfare losses are now stronger. Compared with the benchmark model, the additional parameters are (i) the weighting on producer surplus in the regulator's welfare function $\delta$, (ii) the entire vector of firms' market shares $\left\{\sigma_{1}, \sigma_{2}, \ldots, \sigma_{n}\right\}$, (iii) an assumption, estimate, or bounds for demand curvature $\gamma$, and (iv) an assumption, estimate, or bounds for the ratio of the setup cost to equilibrium consumer surplus $K / S^{*}{ }^{34}$

Given its complexity, welfare losses in this generalized model are perhaps best examined on a case-by-case basis using the actual distribution of market shares from a real-world industry. But the above discussion shows that, in principle, such estimation is feasible (and straightforward) in a practical setting.

I now examine some of the limiting properties of generalized welfare losses. The key step is to recognize that they can be bounded above as follows:

$$
\begin{aligned}
\widehat{L}^{*}(\delta) & =1-\widehat{W}^{*}(\delta) / W^{F B} \text { (by definition) } \\
& \leq 1-S^{*} / W^{F B}\left(\text { since } \widehat{W}^{*}(\delta) \geq S^{*} \text { for any } \delta \in[0,1]\right) \\
& \leq 1-S^{*} / S^{F B}\left(\text { since } S^{F B} \geq W^{F B} \text { for any } K \geq 0\right)
\end{aligned}
$$

So, for any weight on producer surplus $\delta \in[0,1]$ and any fixed cost $K \geq 0$, generalized welfare losses are no greater than welfare losses in terms of consumer surplus, $\widehat{L}^{*}(\delta) \leq 1-S^{*} / S^{F B}$.

\footnotetext{
${ }^{34}$ It is again possible to derive a maximum setup cost using the smallest firm's decision to enter the market because it makes non-negative profits,

$$
\Pi_{\min }^{*} \geq 0 \Leftrightarrow \frac{K}{S^{*}} \leq\left[\frac{(\gamma+1) \sigma_{\min }^{2}}{n-\left(1-\sigma_{\min }\right)(1-\gamma)}\right],
$$

where the right-hand side consists only of parameters for which information or estimates are otherwise already available. (It is easy to check that, as before, a firm with a smaller market share $\sigma_{j}$ makes lower equilibrium profits $\Pi_{j}^{*}$ in the generalized model.)
} 
Since equilibrium consumer surplus relative to its first best is given by

$$
\frac{S^{*}}{S^{F B}}=\left[1+\frac{\gamma \sigma_{\max }}{n-\left(1-\sigma_{\max }\right)(1-\gamma)}\right]^{-(\gamma+1) / \gamma},
$$

the next proposition follows.

Proposition 6 For any $\delta \in[0,1]$, generalized equilibrium welfare losses $\widehat{L}^{*}(\delta)$

(i) tend to zero as the number of firms grows large (as $n \rightarrow \infty$ ) or as demand becomes very convex (as $\gamma \rightarrow-1$ );

(ii) are bounded above by the largest firm's market share, $\widehat{L}^{*}(\delta) \leq \sigma_{\max }$.

Proof. For part (i), note from (40) that $S^{*} / S^{F B}$ increases with the number of firms $n$, and that $\lim _{n \rightarrow \infty}\left(S^{*} / S^{F B}\right)=1$, and also that $\lim _{\gamma \rightarrow-1}\left(S^{*} / S^{F B}\right)=1$. For part (ii), note that $S^{*} / S^{F B}$ decreases with demand curvature $\gamma$, and $\lim _{\gamma \rightarrow \infty}\left(S^{*} / S^{F B}\right)=$ $1-\sigma_{\max }$. The results now follows since $\widehat{L}^{*}(\delta) \leq 1-S^{*} / S^{F B}$ by (39).

Part (i) shows that the finding from previous numerical simulations is general: Welfare losses tend to zero if either the number of firms grows large or if demand becomes very convex. So, importantly, generalized welfare losses with convex demand must, over some range, be lower than in the benchmark case with linear demand.

Part (ii) shows that losses never exceed the largest firm's market share. This result holds across a wide range of models — including all the special cases examined above - and also if the welfare standard is geared towards consumers (with $\delta<1$ ). The general result is, of course, also weaker because the largest market share in an industry is often 20 percent, 30 percent, or higher.

Perhaps the key observation, however, is that welfare losses are not "arbitrary" in this generalized model. In other words, they can not be made arbitrarily close to 100 percent by appropriate choice of parameter values (since $\sigma_{\max }<1$, and, indeed often $\sigma_{\max }<<1$ ). This again stands in sharp contrast to the standard model of Cournot competition with profit-maximizing firms, for which Corchón (2008) shows that welfare losses are indeed arbitrary in some cases.

Two final points arise from the fact that the upper bound on generalized welfare losses $\widehat{L}^{*}(\delta) \leq 1-S^{*} / S^{F B}$ places zero weight on industry profits:

First, Proposition 6 may also apply if the fixed setup cost is allowed to vary across firms as $K_{j}$. Suppose that the first-best outcome still has the firm with $\lambda_{\max }$ producing where $p_{j}\left(X^{F B}\right)=c_{j}$. Then it is easy to check that the argument from (39) that $\widehat{L}^{*}(\delta) \leq 1-S^{*} / S^{F B}$ still holds. Of course, the lower bound on $S^{*} / S^{F B}$ is independent of the $K_{j}$ s, so $\widehat{L}^{*}(\delta) \leq \sigma_{\max }$ continues to apply. 
Second, the upper bound on welfare losses $\widehat{L}^{*}(\delta) \leq \sigma_{\max }$ thus also holds if some — or indeed all — industry profits have been dissipated in form of socially wasteful rent-seeking activities to gain market power (see, e.g., Posner, 1975).

\section{Concluding remarks}

Corporate managers and executive compensation in many industries place significant emphasis on measures of firm size. A model that incorporates such objectives may thus, in some cases, provide a better reflection of industry behaviour than a standard model with profit-maximizing firms. This paper has analyzed welfare losses due to imperfect competition where managers pursue strategic incentives based on sales revenue. ${ }^{35}$ The framework presented also applies to a range of strategically equivalent settings, including competition between oligopsonists (e.g., for retail bank deposits) and strategic forward trading (e.g., in restructured electricity markets).

The results show that, with equilibrium incentives, welfare losses due to imperfect competition are likely to be less than 5 percent for many empirically relevant market structures. Even a relatively small number of firms can be sufficient to yield almost fully competitive outcomes. Their large impact on market performance suggests that firms' strategic incentives may also deserve more attention in antitrust policy, perhaps most notably in merger analysis. In contrast to existing empirical approaches, welfare losses can be estimated using only observable information on firms' market shares (together with an assumption, estimate, or bounds for demand curvature).

What could generate larger welfare losses in industries where managers pursue firm size objectives? First, welfare losses can be significantly higher than 5 percent if firms' demand curves are strongly concave and their market shares are asymmetric in a particular way (see Extension A). Second, losses may also be higher if there are significant fixed costs and "excess entry" relative to first-best (see Extension B). Third, a welfare standard based on consumer surplus — rather than social surplus

\footnotetext{
${ }^{35}$ The other incentive contract considered in the recent literature on delegation is based on a combination of profits and market share. (Jansen, van Lier and van Witteloostuijn (2007) and Ritz (2008) show that market share contracts dominate incentives based on sales revenue in a three-stage game in which symmetric oligopolists can initially choose between different contracts in the additional stage.) For the simple case of a symmetric duopoly with linear demand, Ritz (2008) shows that the strategic effect $\psi^{*}=(1-\sqrt{2})$. Using this in the above framework yields that equilibrium welfare losses $L^{*}=[(\sqrt{2}-1) /(2 \sqrt{2}-1)]^{2}$, or about $4 \frac{1}{2}$ percent. This suggests that the results are likely to be very similar to Proposition 2 above. Based on this, I conjecture that, in general, welfare losses tend to be somewhat — but probably not much — higher with market share contracts. It also seems likely that the limiting cases under which welfare losses go to zero (from part (i) of Proposition 6) should continue to apply with market share incentives.
} 
as in the related literature - would also generate higher losses (see Extension C). Fourth, higher losses may also be the result of collusive agreements between firms in a dynamic model (where managerial incentives might also affect cartel stability). ${ }^{36}$ Finally, it is clear that welfare losses could be substantially higher if firms' products are also significantly horizontally differentiated. ${ }^{37}$

However, it is worth remembering that equilibrium welfare losses would be lower than in the above analysis if the first-best outcome is not attainable in practice. For example, it may simply not be possible for the most efficient firm to supply the entire first-best quantity to the market due to capacity constraints. Moreover, in a setting with fixed costs, it may be difficult for the regulator to compensate a firm for operating losses without creating additional distortions. Welfare losses relative to a "second-best" optimum are generally smaller.

\section{Appendix}

Proof of Proposition 3. For part (i) of the proposition, the first step of the proof shows that $L^{*}=\frac{1}{7}$ is the highest possible welfare loss for a duopoly, and the second step then shows that welfare losses for $n \geq 2$ always satisfy $L^{*} \leq \frac{1}{7}$. For the first step, in the duopoly case with $n=2$, the Herfindahl index $H=\sigma_{\max }^{2}+\left(1-\sigma_{\max }\right)^{2}$ so welfare losses from Proposition 1 become

$$
\left.L^{*}(\cdot)\right|_{n=2}=\frac{\sigma_{\max }^{2}+4\left(2 \sigma_{\max }-1\right)\left(1-\sigma_{\max }\right)}{\left(2+\sigma_{\max }\right)^{2}} \equiv \varphi\left(\sigma_{\max }\right) .
$$

Differentiating this expression gives that

$$
\varphi^{\prime}\left(\sigma_{\max }\right)=\frac{40\left(\frac{4}{5}-\sigma_{\max }\right)}{\left(2+\sigma_{\max }\right)^{4}}
$$

so $\bar{\sigma}_{\max }=\frac{4}{5}$ satisfies $\varphi^{\prime}\left(\bar{\sigma}_{\max }\right)=0$. Since $\varphi^{\prime \prime}\left(\sigma_{\max }\right)<0$, it follows that $\left.L^{*}(\cdot)\right|_{n=2} \leq$ $\varphi\left(\bar{\sigma}_{\max }\right)=\frac{1}{7}$. For the second step, note that $L^{*}\left(n, \sigma_{\max }, H\right)$ is decreasing in $H$. Since the Herfindahl index

$$
H \geq \sigma_{\max }^{2}+\frac{\left(1-\sigma_{\max }\right)^{2}}{(n-1)} \equiv \underline{H}
$$

\footnotetext{
${ }^{36}$ See Lambertini and Trombetta (2002) for an analysis of the incentive to collude in a repeated game with strategic incentives. I am not aware of any work on collusion under delegation with asymmetric firms.

${ }^{37}$ For instance, if products are almost fully horizontally differentiated, firms act almost like independent monopolists (and there is only very little scope for strategic manipulation), so welfare losses are also close to monopoly levels. See also Corchón and Zudenkova (2009).
} 
it follows that $L^{*}\left(n, \sigma_{\max }, H\right) \leq L^{*}\left(n, \sigma_{\max }, \underline{H}\right)$. (Note also that this holds with equality for $n=2$.) Replacing $H$ with $\underline{H}$ in the formula for welfare losses from Proposition 1 and some rearranging shows that $L^{*}\left(n, \sigma_{\max }, \underline{H}\right) \leq \frac{1}{7}$ is equivalent to $\Gamma\left(n, \sigma_{\max }\right) \leq 0$, where

$$
\begin{aligned}
\Gamma\left(n, \sigma_{\max }\right) \equiv & 2 \sigma_{\max }\left(3+\frac{4}{n}\right) \\
& -\left(\frac{n-1}{2}+\frac{7}{n}\right)-\left(7-\frac{3}{n}+\frac{3}{n^{2}}\right) \sigma_{\max }^{2}
\end{aligned}
$$

Differentiating this expression gives that

$$
\frac{1}{2} \frac{\partial \Gamma\left(n, \sigma_{\max }\right)}{\partial \sigma_{\max }}=\left(3+\frac{4}{n}\right)-\left(7-\frac{3}{n}+\frac{3}{n^{2}}\right) \sigma_{\max } .
$$

Since $\partial^{2} \Gamma\left(n, \sigma_{\max }\right) / \partial \sigma_{\max }^{2}<0$, the largest firm's market share that maximizes $\Gamma\left(n, \sigma_{\max }\right)$ solves $\partial \Gamma\left(n, \sigma_{\max }\right) / \partial \sigma_{\max }=0$ and is given by

$$
\sigma_{\max }^{\star}=\frac{\left(3+\frac{4}{n}\right)}{\left(7-\frac{3}{n}+\frac{3}{n^{2}}\right)} .
$$

It follows that $\Gamma\left(n, \sigma_{\max }\right) \leq \Gamma\left(n, \sigma_{\max }^{\star}\right)$. (Note also that $\sigma_{\max }^{\star}=\frac{4}{5}=\bar{\sigma}_{\max }$ for $n=2$.) Now using the expression for $\sigma_{\max }^{\star}$ in the formula for $\Gamma\left(n, \sigma_{\max }\right)$ shows that

$$
\Gamma\left(n, \sigma_{\max }^{\star}\right)=\sigma_{\max }^{\star}\left(3+\frac{4}{n}\right)-\left(\frac{n-1}{2}+\frac{7}{n}\right)
$$

and so $\Gamma\left(n, \sigma_{\max }^{\star}\right) \leq 0$ whenever

$$
\sigma_{\max }^{\star} \leq \frac{\left(\frac{n-1}{2}+\frac{7}{n}\right)}{\left(3+\frac{4}{n}\right)} \equiv \tilde{\sigma}_{\max }
$$

It is easy to confirm that $\sigma_{\text {max }}^{\star} \leq \tilde{\sigma}_{\max }$ indeed holds for all $n \geq 2$ (with equality only for $n=2)$. It follows that $\Gamma\left(n, \sigma_{\max }\right) \leq \Gamma\left(n, \sigma_{\max }^{\star}\right) \leq 0$, which in turn implies that

$$
L^{*}\left(n, \sigma_{\max }, H\right) \leq L^{*}\left(n, \sigma_{\max }, \underline{H}\right) \leq \frac{1}{7}
$$

as claimed. Part (ii) of the proposition now follows trivially by recalling that welfare losses due to monopoly $L_{\text {sym }}^{*}(1)=\frac{1}{4}$ (for example, by setting $n=1$ in Proposition 
2). Part (iii) of the proposition can be seen by rewriting the formula for welfare losses from Proposition 1 as

$$
L^{*}\left(n, \sigma_{\max }, H\right)=\frac{\left(\sigma_{\max } / n\right)^{2}+2\left(\sigma_{\max } / n-H / n\right)}{\left(1+\sigma_{\max } / n\right)^{2}},
$$

and, noting that $\sigma_{\max } \in\left[\frac{1}{n}, 1\right)$ and $H \in\left[\frac{1}{n}, 1\right)$ are both bounded, it follows that

$$
\lim _{n \rightarrow \infty} L^{*}\left(n, \sigma_{\max }, H\right)=0
$$

as claimed.

Proof of Proposition 4. Equilibrium welfare losses $L^{*}\left(n, \sigma_{\max }, H\right)$ are decreasing in $H$, and the Herfindahl index $H \geq \sigma_{\max }^{2}+\left(1-\sigma_{\max }\right)^{2} /(n-1) \equiv \underline{H}$, so $L^{*}\left(n, \sigma_{\max }, H\right) \leq L^{*}\left(n, \sigma_{\max }, \underline{H}\right)$. From the proof of Proposition $2, L^{*}\left(n, \sigma_{\max }, \underline{H}\right) \leq$ $L^{*}\left(n, \sigma_{\max }^{\star}, \underline{H}\right)$, where $\sigma_{\max }^{\star}$ is defined in $(46)$, and note that $L^{*}\left(n, \sigma_{\max }, \underline{H}\right)$ is decreasing in $\sigma_{\max }$ for all $\sigma_{\max } \leq \sigma_{\max }^{\star}$. Since $\sigma_{\max }^{\star} \in\left(\frac{3}{7}, \frac{4}{5}\right]$, it follows that $L^{*}\left(n, \sigma_{\max }, \underline{H}\right) \leq$ $L^{*}\left(n, \frac{7}{20}, \underline{H}\right)$ for any $\sigma_{\max } \leq \frac{7}{20}$. Replacing $H$ with $\underline{H}$ in the formula for welfare losses from Proposition 1 and some rearranging shows that

$$
L^{*}\left(n, \sigma_{\max }, \underline{H}\right)=\frac{(n-1) \sigma_{\max }^{2}+2 n\left(n \sigma_{\max }-1\right)\left(1-\sigma_{\max }\right)}{(n-1)\left(n+\sigma_{\max }\right)^{2}}
$$

and so

$$
L^{*}\left(n, \frac{7}{20}, \underline{H}\right)=\frac{49(n-1)+26 n(7 n-20)}{(n-1)(20 n+7)^{2}} .
$$

Ignoring integer constraints for a moment, it is not difficult to check that $L^{*}\left(n, \frac{7}{20}, \underline{H}\right)$ is increasing (decreasing) in $n$ for $n$ smaller (larger) than $\hat{n} \approx 5.05$, so $L^{*}\left(n, \frac{7}{20}, \underline{H}\right) \leq$ $L^{*}\left(\hat{n}, \frac{7}{20}, \underline{H}\right)$. Since $L^{*}\left(5, \frac{7}{20}, \underline{H}\right) \approx 4.69 \% \geq L^{*}\left(6, \frac{7}{20}, \underline{H}\right) \approx 4.56 \%$, it follows that $L^{*}\left(n, \frac{7}{20}, \underline{H}\right) \leq 4.69 \%$, where the latter is approximately equal to $4 \frac{2}{3} \%$. Therefore

$$
L^{*}\left(n, \sigma_{\max }, H\right) \leq L^{*}\left(n, \sigma_{\max }, \underline{H}\right) \leq L^{*}\left(n, \frac{7}{20}, \underline{H}\right) \leq L^{*}\left(\hat{n}, \frac{7}{20}, \underline{H}\right) \approx 4 \frac{2}{3} \%
$$

for any $\sigma_{\max } \leq \frac{7}{20}$ as claimed.

Proof of Proposition 5. With non-linear demand, by (34), the strategic effect follows from the first-order condition for manager $j$ 's output choice, $\partial \Omega_{j} / \partial x_{j}=0$,

$$
\frac{d X_{-j}}{d x_{j}}=-\left[\frac{(n-1)-\left(1-\sigma_{j}\right)(1-\gamma)}{n-\left(1-\sigma_{j}\right)(1-\gamma)}\right] \equiv \psi_{-j}<0 .
$$

Furthermore, by (35), the first-order condition for firm $j$ 's choice of incentives, 
$d \Pi_{j}^{*} / d \theta_{j}=0$, can be written as

$$
s \lambda_{j}-\left(X^{*}\right)^{\gamma}\left[1+\gamma \sigma_{j}\left(1+\psi_{-j}\right)\right]=0 .
$$

Summing the $n$ first-order conditions from (35) gives

$$
s \sum_{j=1}^{n} \lambda_{j}-\left(X^{*}\right)^{\gamma} \sum_{j=1}^{n}\left[1+\gamma \sigma_{j}\left(1+\psi_{-j}\right)\right]=0 .
$$

Rearranging this shows that equilibrium industry output also satisfies

$$
\left(X^{*}\right)^{\gamma}=\frac{s \sum_{j=1}^{n} \lambda_{j}}{\sum_{j=1}^{n}\left[1+\gamma \sigma_{j}\left(1+\psi_{-j}\right)\right]} .
$$

Combining this with the first-order condition from (55) shows that the firms' profitability indices are related by

$$
\lambda_{j}=\left(\sum_{j=1}^{n} \lambda_{j}\right) \frac{\left[1+\gamma \sigma_{j}\left(1+\psi_{-j}\right)\right]}{\sum_{j=1}^{n}\left[1+\gamma \sigma_{j}\left(1+\psi_{-j}\right)\right]},
$$

and so also

$$
\sum_{j=1}^{n} \lambda_{j} \sigma_{j}=\left(\sum_{j=1}^{n} \lambda_{j}\right) \frac{\left[1+\gamma \sum_{j=1}^{n} \sigma_{j}^{2}\left(1+\psi_{-j}\right)\right]}{\sum_{j=1}^{n}\left[1+\gamma \sigma_{j}\left(1+\psi_{-j}\right)\right]}
$$

The remainder of the proof derives equilibrium consumer surplus, firm and industry profits, generalized welfare, first-best welfare, and, finally, a formula for generalized welfare losses using these expressions.

Recalling the consumer utility function from (30) and the corresponding inverse demand curve for firm $j$ from (31), equilibrium consumer surplus can be written as

$$
S^{*}=\frac{\gamma}{s(\gamma+1)}\left(X^{*}\right)^{\gamma+1}
$$

Now using the expressions for industry output from (57) and the strategic effects from (54) yields

$$
S^{*}=\frac{\gamma}{(\gamma+1)} s^{1 / \gamma}\left[\frac{\sum_{j=1}^{n} \lambda_{j}}{n+\sum_{j=1}^{n}\left\{\frac{\gamma \sigma_{j}}{n-\left(1-\sigma_{j}\right)(1-\gamma)}\right\}}\right]^{(\gamma+1) / \gamma} .
$$

Similarly, using (54), (57), (58), (59), and (61), firm $j$ 's profits $\Pi_{j}=\left(p_{j}-c_{j}\right) x_{j}-$ 
$K$ can, in equilibrium, be written as

$$
\Pi_{j}^{*}=\left[\frac{(\gamma+1) \sigma_{j}^{2}}{n-\left(1-\sigma_{j}\right)(1-\gamma)}\right] S^{*}-K .
$$

Therefore equilibrium industry profits are given by

$$
\sum_{j=1}^{n} \Pi_{j}^{*}=(\gamma+1)(\widetilde{H} / n) S^{*}-n K
$$

where

$$
\widetilde{H} \equiv \sum_{j=1}^{n}\left\{\frac{n \sigma_{j}^{2}}{n-\left(1-\sigma_{j}\right)(1-\gamma)}\right\}
$$

is the industry's adjusted Herfindahl index.

Taken together, the expressions for equilibrium consumer surplus and industry profits imply that generalized welfare, $\widehat{W}(\delta)=S+\delta \sum_{j=1}^{n} \Pi_{j}$, in equilibrium becomes

$$
\widehat{W}^{*}(\delta)=[1+\delta(\gamma+1)(\widetilde{H} / n)] S^{*}-\delta n K
$$

First-best welfare $W^{F B}=\left(S^{F B}-K\right)>0$, where $S^{F B}=[\gamma /(\gamma+1)] s^{1 / \gamma} \lambda_{\max }^{(\gamma+1) / \gamma}$ is first-best consumer surplus. Using (54), (58), and (59), and (61), first-best consumer surplus is related to equilibrium consumer surplus according to

$$
S^{F B}=\left[1+\frac{\gamma \sigma_{\max }}{n-\left(1-\sigma_{\max }\right)(1-\gamma)}\right]^{(\gamma+1) / \gamma} S^{*}
$$

Finally, therefore, generalized welfare losses $\widehat{L}(\delta)=1-\widehat{W}(\delta) / W^{F B}$ are, in equilibrium, given by

$$
\widehat{L}^{*}\left(n, \sigma_{\max }, \widetilde{H}, \gamma, K / S^{*}, \delta\right)=1-\frac{1+\delta\left[(\gamma+1) \frac{\widetilde{H}}{n}-n \frac{K}{S^{*}}\right]}{\left[1+\frac{\gamma \sigma_{\max }}{n-\left(1-\sigma_{\max }\right)(1-\gamma)}\right]^{(\gamma+1) / \gamma}-\frac{K}{S^{*}}},
$$

as claimed. 


\section{References}

Aghion, Philippe and Mark Schankerman (2004). On the welfare effects and political economy of competition-enhancing policies. Economic Journal 114, 800-824.

Alchian, Armen A. (1950). Uncertainty, evolution and economic theory. Journal of Political Economy 58, 211-221.

Ali, Ashiq, Sandy Klasa, and Eric Yeung (2009). The limitations of industry concentration measures constructed with Compustat data: Implications for finance research. Review of Financial Studies 22, 3839-3871.

Allaz, Blaise and Jean-Luc Vila (1993). Cournot competition, forward markets and efficiency. Journal of Economic Theory 59, 1-16.

Anderson, Simon P. and Régis Renault (2003). Efficiency and surplus bounds in Cournot competition. Journal of Economic Theory 113, 253-264.

Berkson, Brad, Gregory Maged, Raj Shah, and Bryan Tantzen (1997). The (new) battle for the US PC market. McKinsey Quarterly, 178-184.

Bresnahan, Timothy F. and Peter C. Reiss (1991). Entry and competition in concentrated markets. Journal of Political Economy 99, 977-1009.

Bushnell, James B., Erin T. Mansur, and Celeste Saravia (2008). Vertical arrangements, market structure, and competition: An analysis of restructured U.S. electricity markets. American Economic Review 98, 237-266.

Caillaud, Bernard, Bruno Jullien, and Pierre Picard (1995). Competing vertical structures: Precommitment and renegotiation. Econometrica 63, 621-646.

Capaldo, Antonio, Philip Härle, and Anna Marrs (2008). What's next for exchanges. McKinsey Quarterly, 1-12.

Clay, Karen and Werner Troesken (2003). Further tests of static oligopoly models: Whiskey, 1882-1898. Journal of Industrial Economics 51, 151-166.

Corchón, Luis C. (2008). Welfare losses under Cournot competition. International Journal of Industrial Organization 26, 1120-1131.

Corchón, Luis C. and Galina Zudenkova (2009). Computing welfare losses from data under imperfect competition with heterogeneous goods. International Journal of Industrial Organization 27, 646-654.

Cowling, Keith and Dennis C. Mueller (1978). The social costs of monopoly power. Economic Journal 88, 727-748.

D'Aspremont, Claude and Louis-André Gérard-Varet. Stackelberg-solvable games and pre-play communication. Journal of Economic Theory 23, 201-217.

Farrell, Joseph and Paul Klemperer (2007). Coordination and lock-in: Competition with switching costs and network effects. In: Mark Armstrong and Robert Porter (eds.), Handbook of Industrial Organization, Volume 3, 1967-2072. Amsterdam: 
Elsevier.

Farrell, Joseph and Carl Shapiro (1990). Horizontal mergers: An equilibrium analysis. American Economic Review 80, 107-126.

Fershtman, Chaim and Kenneth L. Judd (1987). Equilibrium incentives in oligopoly. American Economic Review 77, 927-940.

Fershtman, Chaim and Ehud Kalai (1997). Unobserved delegation. International Economic Review 38, 763-774.

Friedman, Milton (1953). The methodology of positive economics. In: Milton Friedman, Essays in Positive Economics, 3-43. Chicago: University of Chicago Press.

Genesove, David and Wallace P. Mullin (1998). Testing oligopoly models: Conduct and cost in the sugar industry, 1890-1914. RAND Journal of Economics 29, $355-377$.

Green, Richard J. (1999). The electricity contract market in England and Wales. Journal of Industrial Economics 47, 107-124.

Hannan, Timothy A. and Allen N. Berger (1991). The rigidity of prices: Evidence from the banking industry. American Economic Review 81, 938-945.

Harberger, Arnold C. (1954). Monopoly and resource allocation. American Economic Review 44, 77-87.

Hubbard, R. Glenn and Darius Palia (1995). Executive pay and performance: Evidence from the U.S. banking industry. Journal of Financial Economics 39, $105-130$.

Irwin, Douglas A. (1991). Mercantilism as strategic trade policy: The Anglo-Dutch rivalry for the East India trade. Journal of Political Economy 99, 1296-1314.

Jansen, Thijs, Arie van Lier, and Arjen van Witteloostuijn (2007). A note on strategic delegation: The market share case. International Journal of Industrial Organization 25, 531-539.

Katz, Michael L. (1991). Game-playing agents: Unobservable contracts as precommitments. RAND Journal of Economics 22, 307-328.

Katz, Michael L. (2006). Observable contracts as commitments: Interdependent contracts and moral hazard. Journal of Economics $\&$ Management Strategy 15, 685-706.

Klein, Michael A. (1971). A theory of the banking firm. Journal of Money, Credit and Banking 3, 205-218.

Koçkesen, Levent and Efi A. Ok (2004). Strategic delegation by unobservable incentive contracts. Review of Economic Studies 71, 397-424.

Lahiri, Sajal and Yoshiyasu Ono (1988). Helping minor firms reduces welfare. Economic Journal 98, 1199-1202. 
Lambertini, Luca and Marco Trombetta (2002). Delegation and firms' ability to collude. Journal of Economic Behavior and Organization 47, 359-373.

Mahenc, Philippe and François Salanié (2004). Softening competition through forward trading. Journal of Economic Theory 116, 282-293

Mankiw, N. Gregory and Michael D. Whinston (1986). Free entry and social inefficiency. RAND Journal of Economics 17, 48-58.

Murphy, Kevin J. (1999). Executive compensation. In: Orley C. Ashenfelter and David Card (eds.), Handbook of Labor Economics, Volume 3B, 2485-2563. Amsterdam: Elsevier.

Posner, Richard A. (1975). The social costs of monopoly and regulation. Journal of Political Economy 83, 807-827.

Reitman, David (1993). Stock options and the strategic use of managerial incentives. American Economic Review 83, 513-524.

Ritz, Robert A. (2008). Strategic incentives for market share. International Journal of Industrial Organization 26, 586-597.

Rosen, Sherwin (1992). Contracts and the market for executives. In: Lars Wein and Hans Wijkander (eds.), Contract Economics, 181-217. Oxford: Blackwell Publishers.

Schelling, Thomas C. (1960). The Strategy of Conflict. Cambridge: Harvard University Press.

Scherer, Frederic M. and David Ross (1990). Industrial Market Structure and Economic Performance. Boston: Houghton Mifflin Company ( $3^{\text {rd }}$ edition).

Sweeting, Andrew (2007). Market power in the England and Wales wholesale electricity market, 1995-2000. Economic Journal 117, 654-685.

Tirole, Jean (1988). The Theory of Industrial Organization. Cambridge: MIT Press.

Verboven, Frank and Theon van Dijk (2009). Cartel damages and the passing-on defense. Journal of Industrial Economics 57, 457-491.

Vickers, John (1985). Delegation and the theory of the firm. Economic Journal 95, 138-147.

Vickers, John (1995). Concepts of competition. Oxford Economic Papers 47, 1-23.

Yoffie, David B. (1991). Collision course in commercial aircraft: Boeing - Airbus McDonnell Douglas 1991 (A). Harvard Business School Case 319-106.

Zábojnik, Ján (1998). Sales maximization and specific human capital. RAND Journal of Economics 29, 790-802. 